Research Article

\title{
Dynamic Modeling and Active Vibration Isolation of a Noncontact 6-DOF Lorentz Platform Based on the Exponential Convergence Disturbance Observer
}

\author{
Xubin Zhou, ${ }^{1,2}$ Weidong Chen, ${ }^{1}$ Fagang Zhao, ${ }^{2}$ Dapeng Sui, ${ }^{3}$ Qing Xiao $\left(\mathbb{D},{ }^{4}\right.$ Xingtian Liu $\left(\mathbb{D},{ }^{2}\right.$ \\ Liping Zhou, ${ }^{2}$ and Quan Zhang $\mathbb{1}^{4}$ \\ ${ }^{1}$ Academy of Astronautics, Nanjing University of Aeronautics and Astronautics, Nanjing 210016, China \\ ${ }^{2}$ Shanghai Satellite Engineering Institute, Shanghai 201108, China \\ ${ }^{3}$ Shanghai Electro-Mechanical Engineering Institute, Shanghai 201108, China \\ ${ }^{4}$ School of Mechatronic Engineering and Automation, Shanghai University, Shanghai 200072, China
}

Correspondence should be addressed to Quan Zhang; lincolnquan@shu.edu.cn

Received 4 December 2020; Revised 4 March 2021; Accepted 12 March 2021; Published 25 March 2021

Academic Editor: Yong Zhu

Copyright (C) 2021 Xubin Zhou et al. This is an open access article distributed under the Creative Commons Attribution License, which permits unrestricted use, distribution, and reproduction in any medium, provided the original work is properly cited.

In order to study the vibration isolation and positioning performance of the noncontact 6-DOF platform in the space microgravity environment, this paper presented a cosimulation model of a virtual prototype. Based on the model driven by biaxial noncontact Lorentz force actuators (NLFAs), an equivalent dynamic model has been established. In the meanwhile, the 6-DOF sliding mode robust controller with exponential convergence disturbance observer is developed. The mechanical system simulation model was designed using ADAMS, and the corresponding 6-DOF decoupling control system and disturbance observer programs were developed using MATLAB/Simulink. According to the mechatronics simulation results, the system can enable the floating platform to achieve micron-level posture positioning within $0.5 \mathrm{~s}$. In vibration isolation simulation, the disturbance observer can predict the external disturbance input and compensate the control force more accurately so that the floating platform can effectively suppress low-frequency disturbance and step disturbance under the control of the sliding mode controller. And the displacement of the floating platform under the disturbance of $1-100 \mathrm{~Hz}$ frequency sweep is less than $1 \mu \mathrm{m}$.

\section{Introduction}

The existence of microvibration on spacecraft due to different sources has affected aerospace activities [1]. The requirements for suppressing and isolating the microvibration on highprecision spacecraft and sensitive loads are becoming more and more urgent. At present, the methods for isolating microvibration are mainly active vibration isolation and passive vibration isolation. Passive vibration isolation, although simple in structure and strong in reliability, has achieved certain vibration isolation effects limited in the relative high-frequency range, hence powerless for microvibration environments with low-frequency and complex disturbance sources [2-8]. The low-frequency microvibration in the space has a great influence on the accuracy of high-resolution pointing, the use of precision payload, and the accuracy of scientific experimental results of space stations [9]. For optical observation lenses, a relatively small vibration of $10 \mu \mathrm{m}$ in space can achieve an observation error of $500 \mathrm{~km}$ on the ground [10]. Therefore, the research on spacecraft microvibration and its positioning technology has received great attention. Active vibration isolation was gaining more and more attention in the control applications for spatial microvibration disturbance due to its low-frequency control capability. The magnetic suspension vibration isolation platform was widely used in the fields of the ultraquiet platform, precision manufacturing, and precision positioning [11]. This type of platform is mainly used for space exploration, high-resolution Earth observation, remote laser communication, and other scientific and technological activities [12]. 
At present, the research on positioning and vibration isolation platform is divided into two types, namely, micropositioning and vibration isolation platform and macro- and microcombined platform [13]. The most studied active vibration isolation platform is based on the Stewart configuration [14-16], followed by the noncontact vibration isolation platform based on Lorentz force actuators $[12,17-20]$. In addition, there are microvibration active vibration isolation platforms designed according to other different working principles of actuators [21-25].

The noncontact vibration isolation platform was more suitable for microvibration control in a space microgravity environment due to its nonmechanical contact characteristics, where Locke Martin proposed a magnetic-floating vibration isolation system, which realizes the noncontact connection of Stewart configuration through a 6-pole magnetic-floating mechanism, and improves the vibration isolation capability in the low-frequency band by 1 2 orders of magnitude [26]. MVIS-II provided a high-stability platform for vibration-sensitive optical loads on the TacSat-2 satellite platform. The electromagnetic actuation technique separated the load from the platform and controls the load pointing through three electromagnetic actuators [27]. The ARIS electromagnetic actuation system was a full-cabinet active electromagnetic actuator developed under NASA's ATD project. It was mainly composed of 8 single-degree-offreedom actuators, 8 position sensors, 1 controller, and 3 sets of accelerometer components. ARIS was used as a rotating voice coil actuator [28]. The g-LIMIT was a vibration isolation device supplied to the Microgravity Scientific Glove Box MSG, based on the improved STABLE vibration isolation technology. Its biggest feature was the integration and modularization and divided the exciter and measurement system into three identical units. Each unit has a two-axis Lorentz force exciter and a two-axis accelerometer combined with a two-dimensional position. The measuring system greatly simplifies the machining process and assembly complexity [29]. The electromagnetically actuated 3DOF precision planar motion system developed by Tsinghua University provided users with a high-precision motion positioning platform which can be applied in harsh environments [30]. Ren et al. used the same method to establish a 6 -DOF motion differential equation in the stator coordinate system, but the further transformation was required when designing the control algorithm [31].

For the active vibration isolation platform used in the on-orbit work, the ground tests were significant and necessary. The test methods of the prototype mainly included the drop tower method, parabolic flight method, water float method, suspension method, and air suspension method. However, the testing of related prototypes is very costly, and the prototype needs to be diagnosed and improved [32, 33].

Aiming at the control problem of the 6-DOF noncontact platform, $\mathrm{Li}$ and others proposed PID and PD control methods and deduced the transfer function model [34]. Wu and others proposed a redundant degree of freedom platform, including 8 actuators, built a dynamic model of the maglev platform based on dynamic equations in MATLAB/ Simulink and studied the control strategy using the sliding mode control of the saturation function $[12,35]$. In recent years, Mobayen and others have also proposed many new control strategies in the field of sliding mode control [36-39].

In order to solve the problem that the dynamic equation cannot fully reflect the characteristics of the prototype, this paper proposes a method of using ADAMS to build a dynamic model of the 6-DOF platform, shapes the microgravity environment, solves the difficult problem of the experimental environment, and makes the dynamic model closer to the actual prototype. At the same time, we use the S-function in MATLAB/Simulink to design the control program, thereby constructing a virtual prototype of the 6DOF platform. This can make the simulation more suitable for the actual prototype. In terms of control methods, this paper uses a 6-DOF disturbance observer to minimize the chattering characteristics of sliding mode control and conducts joint simulations of multiple disturbance situations to provide theoretical support for the noncontact 6-DOF platform. The cosimulation model was used to simulate and analyze the positioning and vibration isolation performance of the platform, and the working capabilities of the platform were verified.

The rest of the paper is organized as follows. The design of the noncontact 6-DOF vibration isolation platform is described in Section 2. In Section 3, the dynamic equations of the noncontact 6-DOF vibration isolation platform are derived through the Kane method. Then, in Section 4, the general calculation method of the force on the floating platform is derived using the coordinate transformation matrix. The design of a 6 -DOF sliding mode robust controller with disturbance observer based on exponential convergence is proposed in Section 5. The construction of the cosimulation model in ADAMS and MATLAB is introduced in Section 6. In Section 7, the results of the cosimulation are given and analyzed. And the conclusions are given in Section 8. Finally, the future research direction and outlook are proposed.

\section{The Design of the Noncontact 6-DOF Vibration Isolation Platform}

In Figure 1(a), the noncontact 6-DOF platform was hoisted on the hoisting bracket through the latex tube. An enlarged view of the noncontact platform is shown in Figure 1(b). In order to study the vibration isolation and positioning performance of the noncontact 6-DOF platform in the space microgravity environment, this paper proposed a cosimulation model of a virtual prototype shown in Figure 2.

As shown in Figure 2, the lower part is a fixed platform, which is generally connected to a large spacecraft, and the upper part is a floating platform. The floating platform and the fixed platform are connected by three biaxial NLFAs separated by $120^{\circ}$. Each biaxial NLFA can generate force along the tangent to the circular table and force along the $z$ axis. The disturbance force application point is set at a random position of the floating platform, and there are three intersecting disturbance forces. The six active control forces and three disturbance force action points are all fixedly 


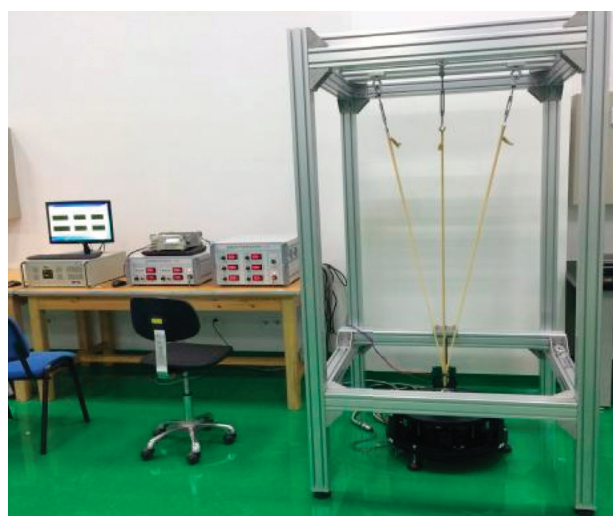

(a)

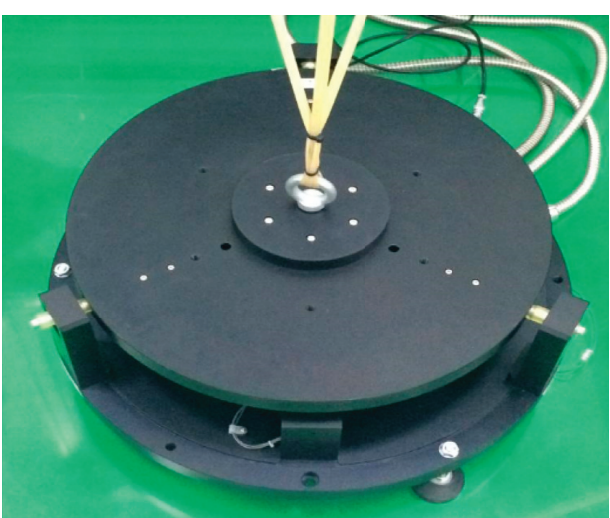

(b)

Figure 1: Test device architecture. (a) Overall structure of test device. (b) Noncontact 6-DOF platform.

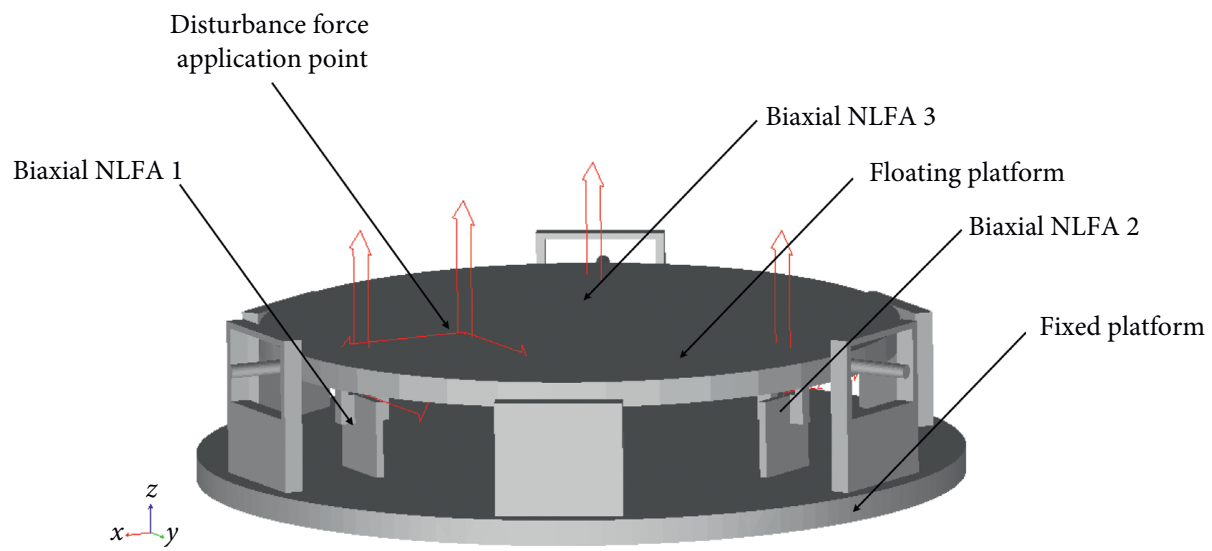

FIgURE 2: Simulation model of mechanical system in ADAMS.

connected to the floating platform, and they are all controlled by the external controller designed in MATLAB/ Simulink. In addition, the position information and acceleration information of the floating platform measured in ADAMS are transmitted to MATLAB/Simulink as feedback information through output variables.

\section{Dynamic Model of the Noncontact 6-DOF Vibration Isolation Platform}

Due to the characteristics of the proposed noncontact 6DOF vibration isolation platform used in a space environment with microgravity, Newton's second law and the Kane method are adopted to develop the dynamic model.

As shown in Figure 3, $N_{0}$ is the inertial coordinate system, $S_{0}$ is the base coordinate system, and $F_{0}$ represents the floating platform coordinate system. $F_{c}^{*}$ and $F_{c}$ are, respectively, the mass of the floating platform in the initial stable state and the position of the mass center after the floating platform moves, while $m$ is the mass of the floating platform. Taking the floating platform as the research object, the vector of six degrees of freedom is used to describe its posture. Define a state-space array $X=\left[\begin{array}{ll}r & \theta\end{array}\right]^{T}$, where $r=$ $\left[\begin{array}{lll}x & y & z\end{array}\right]^{T}$ represents the position of the floating platform

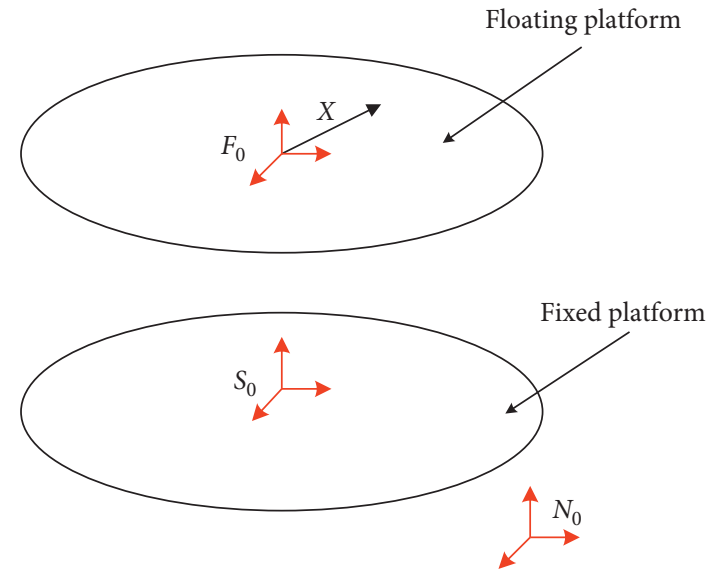

FIGURE 3: Coordinate system relationship.

relative to the base table, and $\theta=\left[\begin{array}{lll}\theta_{x} & \theta_{y} & \theta_{z}\end{array}\right]^{T}$ represents the rotation angle of the floating platform around $x, y$, and $z$ axes, respectively. Then, the resultant forces and moments on the floating platform can be regarded as $F=$ $\left[\begin{array}{lll}F_{x} & F_{y} & F_{z}\end{array}\right]^{T}$ and $M=\left[\begin{array}{lll}M_{x} & M_{y} & M_{z}\end{array}\right]^{T}$, respectively.

In addition, based on the Euler angles and coordinate transformation laws, the conversion matrix from the inertial 
platform coordinate system to the floating platform can be derived as

$$
{ }^{(S / F)} \Gamma=\left[\begin{array}{ccc}
\cos y \cos z & \sin x \sin y \cos z-\cos x \sin z \cos x \sin y \cos z+\sin x \sin z \\
\cos y \sin z & \sin x \sin y \sin z+\cos x \cos z & \cos x \sin y \sin z-\sin x \cos z \\
-\sin y & \sin x \cos y & \cos x \cos y
\end{array}\right]
$$

The Newtonian equations for the floating platform are formulated as

$$
F=m \cdot I_{3 \times 3} \cdot \ddot{X}
$$

Write the rotation equation of the floating platform as matrix form related to state variable $X$ by using the Kane method:

$$
M=\left[0_{3 \times 3}{ }^{(S / F)} \Gamma \cdot J_{F}\right]_{3 \times 6} \cdot \ddot{X} .
$$

In summary, the differential equation of motion of the floating platform can be reorganized as follows:

$$
\left[\begin{array}{c}
F \\
M
\end{array}\right]=\left[\begin{array}{cc}
m \cdot I_{3 \times 3} & 0 \\
0_{3 \times 3} & (S / F) \Gamma
\end{array} \cdot J_{F}\right] \cdot \ddot{X} .
$$

\section{Force Derivation of the Floating Platform}

4.1. Calculation of the Driving Force. According to the Lorentz actuator used, the driving force of the actuator is as follows:

$$
F_{a}=I L B \sin (I, B)
$$

where $I$ is the magnitude of the current, $L$ is the length of the winding coil, and $B$ is the magnetic field strength. Considering that the driving displacement of the actuator is a minimum value, and when the positions of the coil and the magnetic field are determined, the output force and current remained relatively good linearity, and then the formula is simplified as follows:

$$
F_{a}=K_{a} I_{A}
$$

The six driving forces are generated by the three biaxial NLFAs, and the matrix form is shown as follows:

$$
F_{A}=\left[\begin{array}{llllll}
F_{1 z} & F_{1 x} & F_{2 z} & F_{2 x} & F_{3 z} & F_{3 x}
\end{array}\right]^{T} .
$$

The coil current intensity matrix corresponding to the six driving forces is

$$
I_{A}=\left[\begin{array}{llllll}
I_{1 z} & I_{1 x} & I_{2 z} & I_{2 x} & I_{3 z} & I_{3 x}
\end{array}\right]^{T} .
$$

In Figure 4, the direction matrix of the six drivers in the floating platform coordinate system $F_{0}$ is

$$
\left[P^{T}\right]=\left[\begin{array}{c}
P_{F 1 z}^{T} \\
P_{F 1 x}^{T} \\
P_{F 2 z}^{T} \\
P_{F 2 x}^{T} \\
P_{F 3 z}^{T} \\
P_{F 3 x}^{T}
\end{array}\right]=\left[\begin{array}{ccc}
0 & 0 & 1 \\
0 & 1 & 0 \\
0 & 0 & 1 \\
-\frac{\sqrt{3}}{2} & -\frac{1}{2} & 0 \\
0 & 0 & 1 \\
\frac{\sqrt{3}}{2} & -\frac{1}{2} & 0
\end{array}\right] .
$$

Assuming that the vertical distance between the electromagnetic driving force acting point and the floating platform coordinate system is $d_{v}$ and the horizontal distance is $r_{f}$, then the position matrix of the six driving force acting points in the floating platform coordinate system $F_{0}$ is

$$
\left[R^{T}\right]=\left[\begin{array}{l}
R_{F 1 z}^{T} \\
R_{F 1 x}^{T} \\
R_{F 2 z}^{T} \\
R_{F 2 x}^{T} \\
R_{F 3 z}^{T} \\
R_{F 3 x}^{T}
\end{array}\right]=\left[\begin{array}{ccc}
r_{f} & 0 & -d_{v} \\
r_{f} & 0 & -d_{v} \\
-\frac{r_{f}}{2} & \frac{\sqrt{3} r_{f}}{2} & -d_{v} \\
-\frac{r_{f}}{2} & \frac{\sqrt{3} r_{f}}{2} & -d_{v} \\
-\frac{r_{f}}{2} & -\frac{\sqrt{3} r_{f}}{2} & -d_{v} \\
-\frac{r_{f}}{2} & -\frac{\sqrt{3} r_{f}}{2} & -d_{v}
\end{array}\right] .
$$

Then, the resultant force of the three two-axis actuators can be expressed in the inertial coordinate system as

$$
F_{S A}=\sum_{a=1}^{6} F_{a}={ }^{(S / F)} \Gamma \cdot P \cdot F_{A} .
$$

The total torque can be expressed as

$$
M_{S A}=\sum_{a=1}^{6}\left({ }^{(S / F)} \Gamma \cdot R_{F} \times F_{a}\right) .
$$




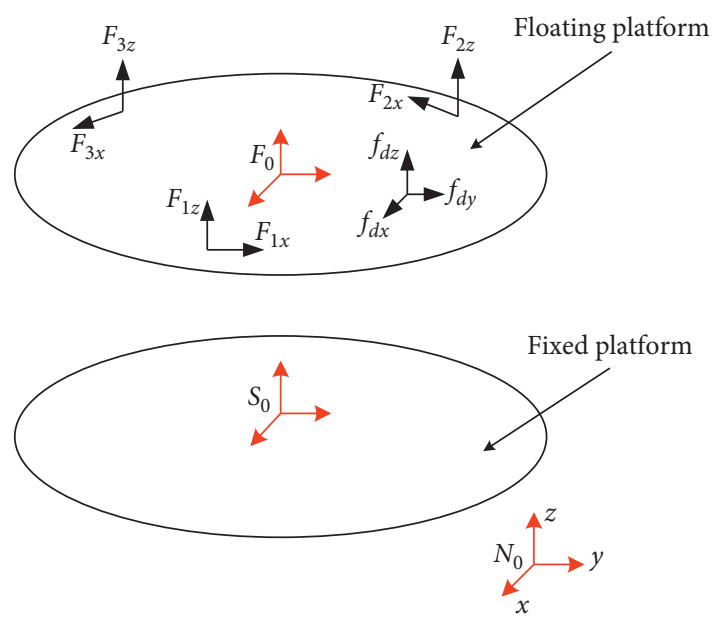

FIgURE 4: Force analysis of the floating platform.

4.2. Calculation of the Disturbance Force. Define the disturbance force acting directly on the floating platform as $f_{d}$; then, the disturbance force in the inertial coordinate system can be expressed as

$$
F_{d}={ }^{(S / F)} \Gamma \cdot f_{d}
$$

where $f_{d}=\left[\begin{array}{lll}f_{d x} & f_{d y} & f_{d z}\end{array}\right]^{T}$.

The torque acting directly on the floating platform can be expressed as

$$
M_{d}=\left(r_{d}-r_{c}\right) \times f_{d}={ }^{(S / F)} \Gamma \cdot r_{f d} \times{ }^{(S / F)} \Gamma \cdot f_{d},
$$

where $r_{f d}$ is the position vector from the center of mass of the floating platform to the point of disturbance force.

4.3. The Resultant Force and Moment on the Floating Platform. The resultant force acting directly on the floating platform can be expressed as

$$
F=F_{S A}+F_{d}
$$

The total torque acting directly on the floating platform can be expressed as

$$
M=M_{S A}+M_{d}
$$

In summary, the dynamic equation of the system is

$$
\left[\begin{array}{c}
F_{S A}+F_{d} \\
M_{S A}+M_{d}
\end{array}\right]=\left[\begin{array}{cc}
m I_{3 \times 3} & 0 \\
0_{3 \times 3} & (S / F) \Gamma
\end{array} J_{F}\right] \ddot{X} .
$$

According to the $3 \mathrm{D}$ modeling data in the CREO software, we can know from Table 1 the model's main parameters.

\section{Design of 6-DOF Sliding Mode Robust Controller with Disturbance Observer Based on Exponential Convergence}

In this section, the disturbance observer based on exponential convergence is used to observe the disturbance force of the floating platform in six degrees of freedom combined
TABLE 1: Model's main parameter table.

\begin{tabular}{lcc}
\hline Parameters & Numerical value & Unit \\
\hline$r_{f}$ & 0.19232 & $\mathrm{~m}$ \\
$d_{v}$ & 0.01574 & $\mathrm{~m}$ \\
$J_{x x}$ & 0.17391 & $\mathrm{~kg} \cdot \mathrm{m}^{2}$ \\
$J_{y y}$ & 0.17391 & $\mathrm{~kg} \cdot \mathrm{m}^{2}$ \\
$J_{z z}$ & 0.34681 & $\mathrm{~kg} \cdot \mathrm{m}^{2}$ \\
$r_{f d}$ & {$[0.1,0,0]$} & - \\
$m$ & 11 & $\mathrm{~kg}$ \\
\hline
\end{tabular}

with the six degrees of freedom sliding mode robust controller to design the control system. In addition, we use PID control for comparison.

5.1. Design of Disturbance Observer Based on Exponential Convergence. According to the dynamic differential equation of the floating platform,

$$
M_{x} \ddot{X}=F_{u}+F_{v} .
$$

During the control process, if the size of the disturbance $F_{v}$ can be effectively observed, the control effect will be greatly improved. The basic idea of designing an observer is to correct the estimated value by the difference between the estimated output and the actual output.

Take $\widehat{F}_{v}=K\left(F_{v}-\widehat{F}_{v}\right)$, where $K>0$.

The auxiliary parameter vector is defined as

$$
z=\widehat{F}_{v}-K M_{x} \dot{X},
$$

and then,

$$
\dot{z}=\dot{\widehat{F}}_{v}-K M_{x} \ddot{X}
$$

Since

$$
\widehat{\widehat{F}}_{v}=K\left(F_{v}-\widehat{F}_{v}\right)=-K \widehat{F}_{v}+K\left(M_{x} \ddot{X}-F_{u}\right),
$$

the following equation is obtained:

$$
\dot{z}=-K \widehat{F}_{v}+K\left(M_{x} \ddot{X}-F_{u}\right)-K M_{x} \ddot{X}=-K F_{u}-K \widehat{F}_{v} .
$$

The disturbance observer is designed as

$$
\begin{gathered}
\dot{z}=-K F_{u}-K \widehat{F}_{v}, \\
\widehat{F}_{v}=z+K M_{x} \dot{X} .
\end{gathered}
$$

Then,

$$
\dot{z}=-K F_{u}-K\left(z+K M_{x} \dot{X}\right)=K\left(-F_{u}-K M_{x} \dot{X}\right)-K z .
$$

It is generally believed that there is no prior knowledge of disturbance $F_{v}$. Relative to the dynamic characteristics of the observer, the change of disturbance $F_{v}$ is slow; that is, $\dot{F}_{v}=0$. Then, the observation error is

$$
\widetilde{F}_{v}=F_{v}-\widehat{F}_{v} .
$$

So, 


$$
\begin{aligned}
\dot{\widetilde{F}}_{v} & =\dot{F}_{v}-\dot{\widehat{F}}_{v}=-\dot{\widehat{F}}=-\dot{z}-K M_{x} \ddot{X} \\
& =-K F_{u}-K\left(z+K M_{x} \dot{X}\right) \\
& =K\left(F_{u}+K M_{x} \dot{X}\right)+K z-K M_{x} \ddot{X} \\
& =K\left(z+K M_{x} \dot{X}\right)-K\left(M_{x} \ddot{X}-F_{u}\right) \\
& =K \widehat{F}_{v}-K F_{v}=-K\left(\widehat{F}_{v}-F_{v}\right)=-K \widetilde{F}_{v} .
\end{aligned}
$$

Thus, the equation for the observation error can be obtained:

$$
\dot{\widetilde{F}}_{v}+K \widetilde{F}_{v}=0 .
$$

Solving the differential equation, we have

$$
\widetilde{F}_{v}(t)=\widetilde{F}_{v}\left(t_{0}\right) e^{-K t} .
$$

Since the value of $\widetilde{F_{v}}\left(t_{0}\right)$ is determined, it can be seen that the convergence accuracy of the 6-DOF observer depends on the parameter matrix $K$. By designing the parameter matrix $K$, the estimated value $\widehat{F}_{v}$ approaches $F_{v}$ exponentially.

5.2. Sliding Mode Control Based on Approach Rate. The main reasons for the wide application of sliding mode control are the good control performance for nonlinear systems, the applicability to MIMO systems, and the establishment of good design standards for discrete-time systems. The important advantage of sliding mode control is its robustness. When the system is in sliding mode, it has excellent insensitivity to the model error of the controlled object, changes in object parameters, and external disturbances.

The errors and their derivatives are $e^{D}=X_{0}^{D}-X^{D}$ and $\dot{e}^{D}=\dot{X}_{0}^{D}-\dot{X}^{D}$, respectively, where $X_{0}^{D}$ is the desired state of the floating platform after vibration isolation.

The slip face is defined as

$$
s=c e^{D}+\dot{e}^{D},
$$

where $c>0$ satisfies the Hurwitz condition.

According to Lyapunov's second criterion, let $V=(1 / 2)$ $s^{2} \geq 0$; then, $\dot{V}=s \dot{s} \leq 0$.

Using the exponential approach law, one has

$$
\dot{s}=-\varepsilon \operatorname{sgn} s-k s,
$$

where $\varepsilon>0, k>0$; construct $\dot{V}=s \dot{s}=-k s^{2} \leq 0$; then,

$$
\dot{s}=c \dot{e}^{D}+\ddot{e}^{D}=c \dot{e}^{D}+\ddot{X}_{0}^{D}-\frac{F_{u}+F_{v}}{M_{x}} .
$$

Then, combining formulas (39) and (40), one can get

$$
c \dot{e}^{D}+\ddot{X}_{0}^{D}-\frac{F_{u}+F_{v}}{M_{x}}=-\varepsilon \text { sgn } s-k s .
$$

Then, the sliding mode control law can be defined as

$$
F_{u}=M_{x}\left(c e^{D}+X_{0}^{D}+\varepsilon s g n s+k s\right)-F_{v} .
$$

Obviously, because the disturbance $F_{v}$ is unknown, the above control law cannot be realized. In order to solve this problem, the control law can be designed using the boundary of disturbance.

The design sliding mode control law is

$$
F_{u}=M_{x}\left(c e^{D}+X_{0}^{D}+\varepsilon s g n s+k s\right)-\widetilde{F}_{v},
$$

where $\widetilde{F_{v}}$ is a positive real number to be designed related to the boundary of disturbance.

Then,

$$
\dot{s}=-\varepsilon \operatorname{sgn} s-k s+\widetilde{F_{v}}-F_{v} .
$$

We select the appropriate $\widetilde{F}_{v}$ to ensure the stability of the control system, that is, to meet the sliding mode arrival conditions.

Suppose that $F_{\text {vlower }} \leq F_{v} \leq F_{\text {vupper }}$, where $F_{\text {vlower }}$ and $F_{\text {vupper }}$ are the underworld and upper bounds of disturbance, respectively.

The selection principles of $\widetilde{F}$ are as follows:

(1) When $s>0, \dot{s}=-\varepsilon-k s+\widetilde{F}_{v}-F_{v}$; in order to ensure $\dot{s}<0$, take $\widetilde{F}_{v}=F_{\text {vlower }}$.

(2) When $s<0, \dot{s}=\varepsilon-k s+\widetilde{F}_{v}-F_{v}$; in order to ensure $\dot{s}<0$, take $\widetilde{F}_{v}=F_{\text {vupper }}$.

Taking $F_{v 1}=\left(F_{v \text { upper }}-F_{\text {vlower }}\right) / 2$ and $F_{v 2}=\left(F_{\text {vupper }}+\right.$ $\left.F_{\text {vlower }}\right) / 2$, you can design $\widetilde{F}_{v}$ that meets the above two conditions:

$$
\widetilde{F_{v}}=F_{v 2}-F_{v 1} \text { sgns. }
$$

The coefficient matrix in the simulation is set as follows:

$$
\begin{aligned}
c & =\left[\begin{array}{cccccc}
15 & 0 & 0 & 0 & 0 & 0 \\
0 & 15 & 0 & 0 & 0 & 0 \\
0 & 0 & 15 & 0 & 0 & 0 \\
0 & 0 & 0 & 15 & 0 & 0 \\
0 & 0 & 0 & 0 & 15 & 0 \\
0 & 0 & 0 & 0 & 0 & 15
\end{array}\right], \\
k & =\left[\begin{array}{cccccc}
10 & 0 & 0 & 0 & 0 & 0 \\
0 & 10 & 0 & 0 & 0 & 0 \\
0 & 0 & 10 & 0 & 0 & 0 \\
0 & 0 & 0 & 10 & 0 & 0 \\
0 & 0 & 0 & 0 & 10 & 0 \\
0 & 0 & 0 & 0 & 0 & 10
\end{array}\right], \\
\varepsilon & =\left[\begin{array}{cccccc}
10^{-5} & 0 & 0 & 0 & 0 & 0 \\
0 & 10^{-5} & 0 & 0 & 0 & 0 \\
0 & 0 & 10^{-5} & 0 & 0 & 0 \\
0 & 0 & 0 & 10^{-5} & 0 & 0 \\
0 & 0 & 0 & 0 & 10^{-5} & 0 \\
0 & 0 & 0 & 0 & 0 & 10^{-5}
\end{array}\right] .
\end{aligned}
$$


5.3. PID Controller Design. Let $e^{D}=X_{0}^{D}-X^{D}$ (the superscript $D$ is the absolute movement), where $X_{0}^{D}$ is the absolute displacement after vibration isolation. The differential equation of the system can be written as

$$
M_{x} \ddot{X}=F_{u}+F_{v} .
$$

In order to facilitate the analysis, let the displacement disturbance $R_{d 0}=\left[\begin{array}{ll}R_{0} & 0_{3 \times 1}\end{array}\right]^{T}$, according to the relationship between the absolute quantity and the relative quantity, we can get

$$
X=X^{D}-R_{d 0}=X_{0}^{D}-e^{D}-R_{d 0} .
$$

Bringing the error $e^{D}$ into the kinetic equation will give

$$
M_{x}\left(-\ddot{e}^{D}+\ddot{R}_{d 0}\right)=F_{u}+F_{v} .
$$

According to the PID control principle, set the control law as

$$
F_{u}=K_{a} \ddot{e}^{D}+K_{d} \dot{e}^{D}+K_{p} e^{D}+K_{i} \int e^{D} \mathrm{~d} t-M_{x} \ddot{R}_{0}-F_{v} .
$$

At this time, since the movement displacement of the fixed platform relative to the inertial coordinate system is a minimum value, in order to verify the control performance, it can be assumed that the fixed platform coordinate system and the inertial platform coordinate system are fixed. Then. $R_{0}$ is a zero matrix.

Then, the dynamic equation with PID control then becomes

$$
\left(M_{x}+K_{a}\right) \ddot{e}^{D}+K_{d} \dot{e}^{D}+K_{p} e^{D}+K_{i} \int e^{D} \mathrm{~d} t+F_{v}=0 .
$$

Since the system is a microvibration isolation platform, its disturbance input $F_{v}$ is bounded. After adding the control force, the value of $K_{p}$ is equivalent to increasing the elastic stiffness of the system, which can effectively suppress the low-frequency vibration of the system; $K_{d}$ is equivalent to increasing the damping of the system, so that the vibration of the system gradually decreases; $K_{i}$ is the displacement. The coefficient of deviation integral is helpful to reduce the positional static error of the system; $K_{a}$ is equivalent to increasing the mass and rotational inertia of the floating platform, making the system insensitive to external disturbance. Then, the whole system belongs to a system where the external input is bounded and the energy continues to decay. According to the definition of Lyapunov's second law, it can be determined that the PID control algorithm can make the system effectively converge.

The coefficient matrix of 6-DOF PID control selected in this paper is as follows:

$$
K_{p}=\left[\begin{array}{cccccc}
100 & 0 & 0 & 0 & 0 & 0 \\
0 & 100 & 0 & 0 & 0 & 0 \\
0 & 0 & 100 & 0 & 0 & 0 \\
0 & 0 & 0 & 100 & 0 & 0 \\
0 & 0 & 0 & 0 & 100 & 0 \\
0 & 0 & 0 & 0 & 0 & 100
\end{array}\right],
$$$$
K_{d}=\left[\begin{array}{cccccc}
20 & 0 & 0 & 0 & 0 & 0 \\
0 & 20 & 0 & 0 & 0 & 0 \\
0 & 0 & 20 & 0 & 0 & 0 \\
0 & 0 & 0 & 20 & 0 & 0 \\
0 & 0 & 0 & 0 & 20 & 0 \\
0 & 0 & 0 & 0 & 0 & 20
\end{array}\right],
$$$$
K_{i}=\left[\begin{array}{cccccc}
15 & 0 & 0 & 0 & 0 & 0 \\
0 & 15 & 0 & 0 & 0 & 0 \\
0 & 0 & 15 & 0 & 0 & 0 \\
0 & 0 & 0 & 15 & 0 & 0 \\
0 & 0 & 0 & 0 & 15 & 0 \\
0 & 0 & 0 & 0 & 0 & 15
\end{array}\right],
$$

$$
K_{a}=\left[\begin{array}{cccccc}
100 & 0 & 0 & 0 & 0 & 0 \\
0 & 80 & 0 & 0 & 0 & 0 \\
0 & 0 & 80 & 0 & 0 & 0 \\
0 & 0 & 0 & 100 & 0 & 0 \\
0 & 0 & 0 & 0 & 100 & 0 \\
0 & 0 & 0 & 0 & 0 & 100
\end{array}\right] \text {. }
$$

\section{Construction of the Cosimulation Model in ADAMS and MATLAB}

As shown in Figure 5, the dynamic equations module is a 6DOF vibration isolation platform model established based on dynamic equations, and the ADAMS_submodule is a 6DOF system model obtained by modeling by the ADAMS software. The disturbance observer module is a packaged disturbance observer based on exponential convergence. The controller module contains two methods of PID and sliding mode variable structure control.

\section{Cosimulation Results and Analysis of ADAMS and MATLAB}

7.1. Research on Platform Position and Posture Control. The position and posture positioning results of millimeter level and micrometer level are, respectively, shown in Figures 6 and 7. Sliding mode control takes much less time to reach the desired position than PID control. Among them, the adjustment time of PID control is about $5 \mathrm{~s}$, while the adjustment time of sliding mode control is only less 


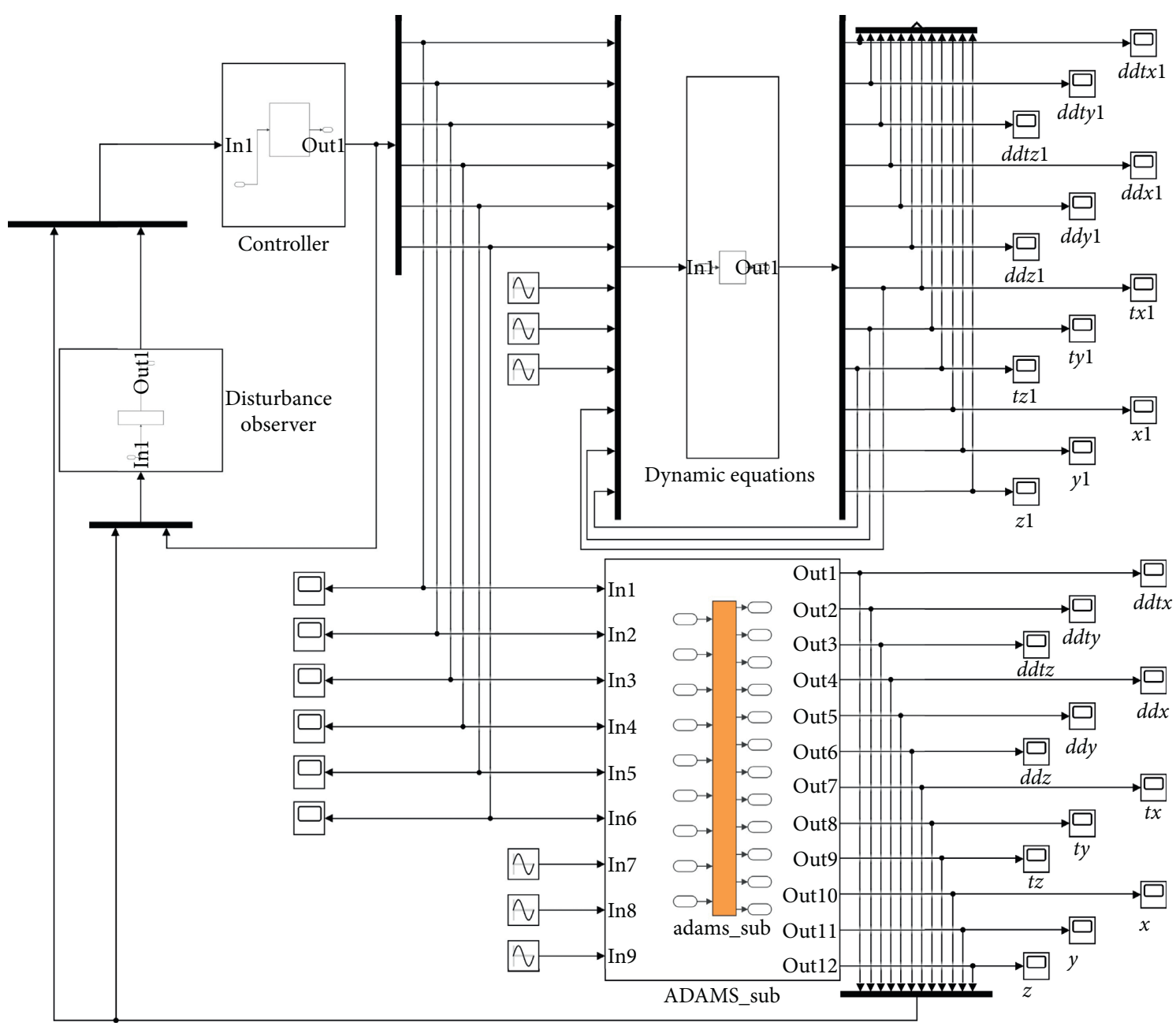

FIgURE 5: The cosimulation model of ADAMS and MATLAB.

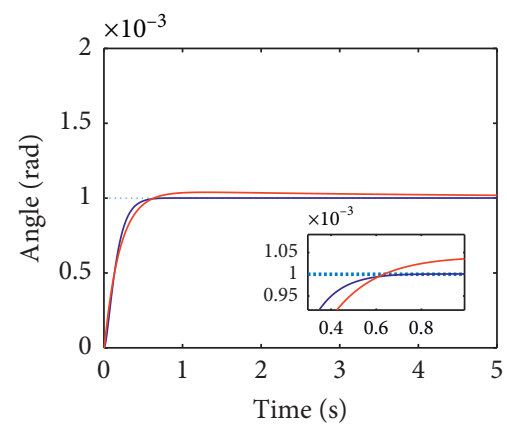

Desired position

Sliding mode control

PID control

(a)

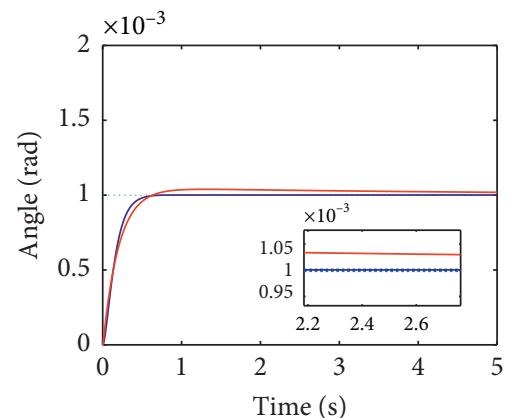

Desired position

Sliding mode control

PID control

(b)

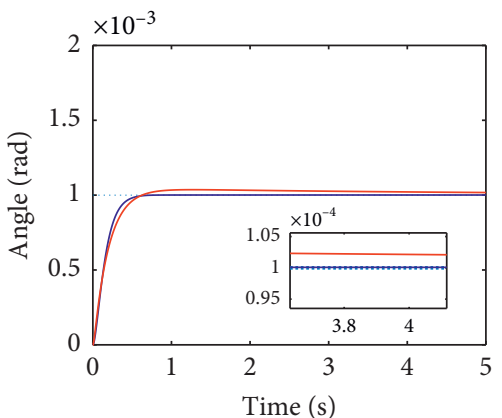

Desired position

Sliding mode control

PID control

(c)

Figure 6: Continued. 


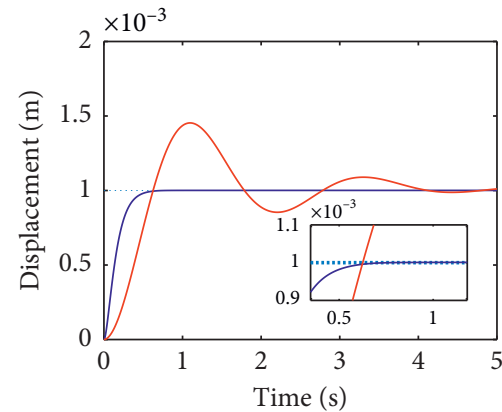

Desired position

— Sliding mode control

_ PID control

(d)

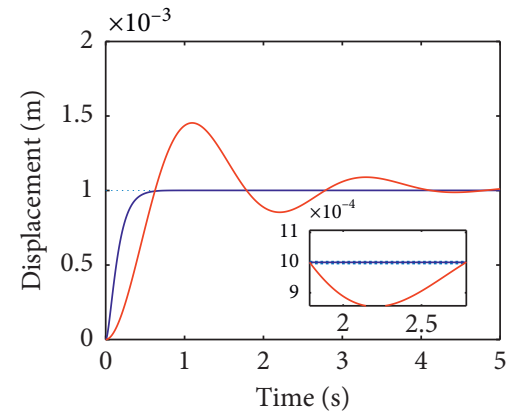

Desired position

Sliding mode control

PID control

(e)

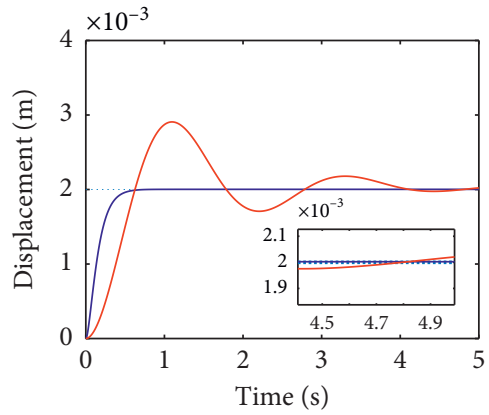

Desired position

_ Sliding mode control

_ PID control

Figure 6: Large displacement (millimeter level) positioning test.

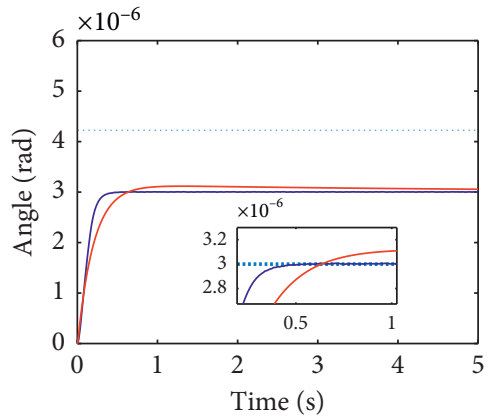

Desired position

Sliding mode control

— PID control

(a)

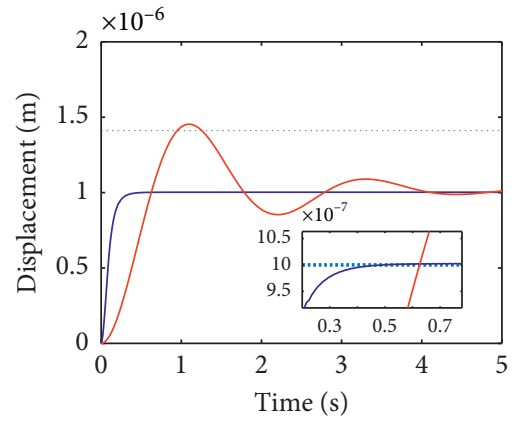

Desired position

— Sliding mode control

— PID control

(d)

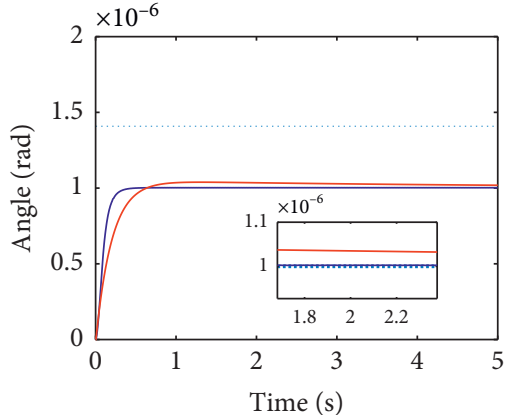

Desired position

Sliding mode control

— PID control

(b)

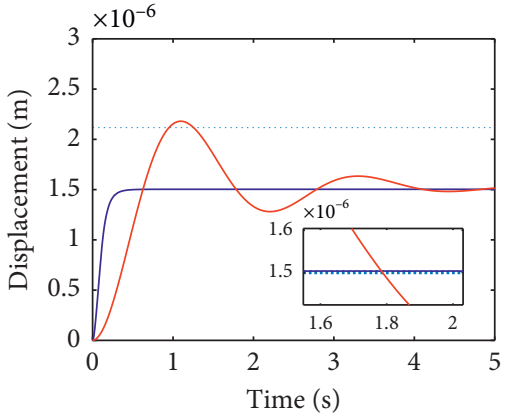

Desired position

Sliding mode control

PID control

(e)

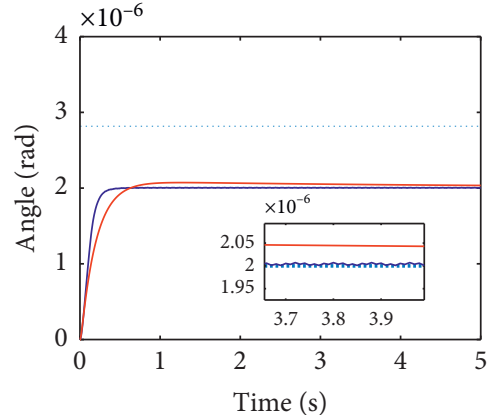

Desired position

- Sliding mode control

_ PID control

(c)

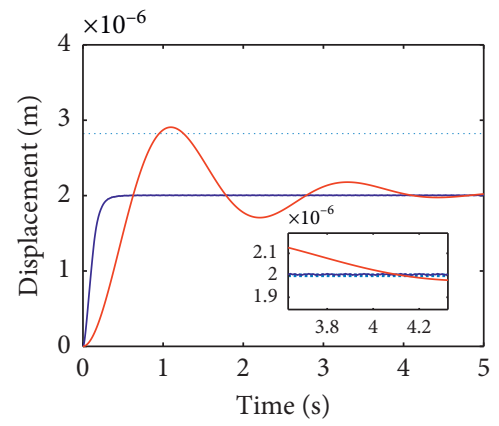

Desired position

- Sliding mode control

— PID control

(f)

Figure 7: Tiny displacement (micron level) positioning test: (a) $\theta_{x}$, (b) $\theta_{y}$, (c) $\theta_{z}$, (d) $x$, (e) $y$, and (f) $z$.

than $10 \%$ of PID control, and the position adjustment of the floating platform can be completed within $0.5 \mathrm{~s}$. Moreover, the adjustment amplitude of sliding mode control is very small, only less than 5\% of PID control on average. Although the sliding mode control will have a slight jitter after reaching the desired position, the magnitude is small and will not affect the control effect. The simulation results show that sliding mode control can adjust the position and attitude of the floating platform greatly. 


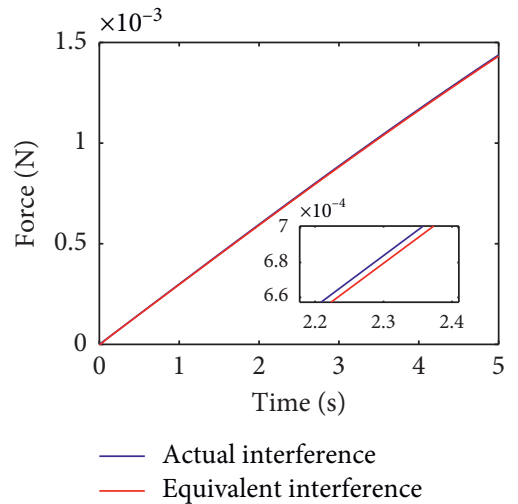

(a)

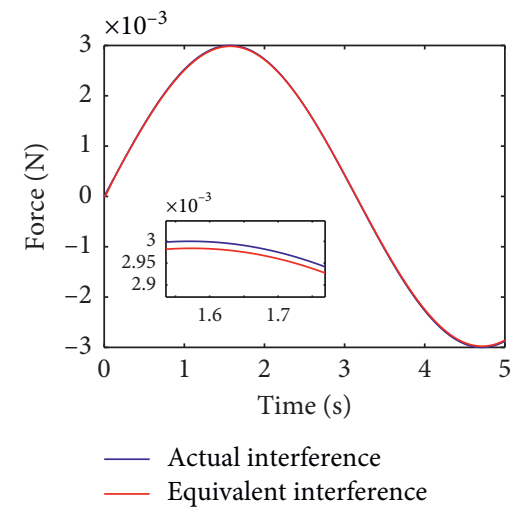

(b)

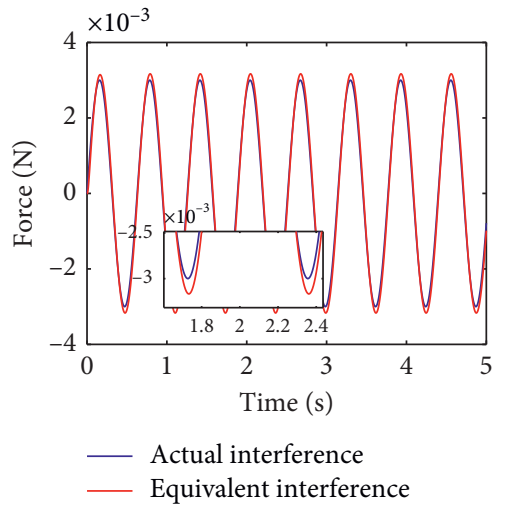

(c)

Figure 8: Test results of disturbance observer: (a) $f_{d x}$, (b) $f_{d y}$, and (c) $f_{d z}$.

\subsection{Research on Platform Vibration Control}

7.2.1. Vibration Isolation Scenario 1. The vibration source is set at the position of the floating platform coordinate system $(0,0.1,0)$, and the $x, y$, and $z$ axes of the vibration source are, respectively, set to have an amplitude of $3 \mathrm{mN}$ and a frequency of $0.1 \mathrm{~Hz}, 1 \mathrm{~Hz}$, and $10 \mathrm{~Hz}$. Sinusoidal excitation disturbance signal is used to analyze the movement state of the six degrees of freedom before and after the control of the platform.

Disturbance observers are added to both PID control and sliding mode control. The disturbance observer designed in this paper can estimate the six degrees of freedom disturbance based on the motion information on the floating platform and the input of the control force. In order to facilitate the analysis of the relationship between the observation results of the disturbance observer and the actual input disturbance, the 6-DOF disturbance observation results can be used in combination with the location information of the disturbance source to solve the $x, y$, and $z$ axes' observation disturbance forces at the input of the disturbance source. Then, we compare the observed disturbance force with the actual input disturbance signal.

It can be seen in Figure 8 that the observer has a strong ability to observe low and medium frequency disturbance, and the phase difference between the observed signal and the actual signal is about $0.2 \mathrm{~s}$, which can fit the actual disturbance signal well.

Figure 9 shows the displacement and attitude control of the floating platform. The results show that both control methods can control the displacement and rotation angle around 0 .

Figure 10 shows the control of floating platform acceleration and angular acceleration. The results show that the two control methods can reduce the acceleration of each axis and the angular acceleration by more than $90 \%$. The enlarged diagram shows that, after the control, the static characteristics of PID will be better than the sliding mode control.

According to Figure 11, from a macroperspective, the control force of the actuators of the two control methods is basically the same, but the partially enlarged view shows that the control force of the sliding mode control will have a certain degree of chatter.
7.2.2. Vibration Isolation Scenario 2. A $3 \mathrm{mNstep}$ disturbance signal is applied to the eccentric vibration source in the $x, y$, and $z$ directions.

In Figure 12, it can be seen that the disturbance observer can better fit the actual disturbance signal in the $x, y$, and $z$ directions of the disturbance source. At 0 and $1 \mathrm{~s}$, when the disturbance signal suddenly changes, the disturbance observer can be adjusted within $0.2 \mathrm{~s}$, so that the observed signal better fits the actual disturbance signal.

In Figure 13, PID control and sliding mode control can well control the position and attitude of the 6-DOF platform. However, it can be seen from Figure 14 that, in the face of sudden disturbance, the sliding mode control is robust and can better control the acceleration of the platform, making the acceleration floating range only less than $20 \%$ of the PID control. In the meantime, Figure 15 shows the control force input required for PID control and sliding mode control. Therefore, sliding mode control is more suitable for irregular and tiny vibrations in space.

7.2.3. Vibration Isolation Scenario 3. There is a $0.1-100 \mathrm{~Hz}$ frequency sweep disturbance system response. Without control, the platform movement scale is relatively large, so here only PID control and sliding mode control are compared.

In the frequency sweep disturbance simulation, it can be seen from Figure 16 that the two control methods can effectively control the pose of the floating platform to keep it relatively static with the base station, and the accuracy can reach the micron level.

7.2.4. Vibration Isolation Scenario 4. The $x, y$, and $z$ axes of the disturbance force application point all have a disturbance force of $1 \mathrm{~N}$ and a frequency of $20 \mathrm{~Hz}$. This part mainly explores the influence of the different coefficients of the disturbance observer on the $z$-axis displacement of the floating platform.

The coefficient matrix $K$ of the disturbance observer with six degrees of freedom can be expressed as 

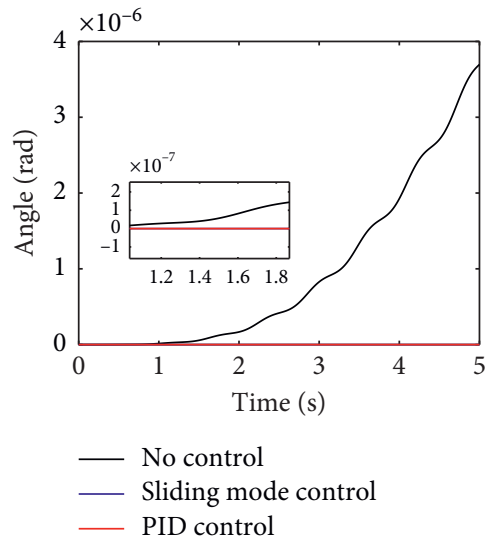

(a)
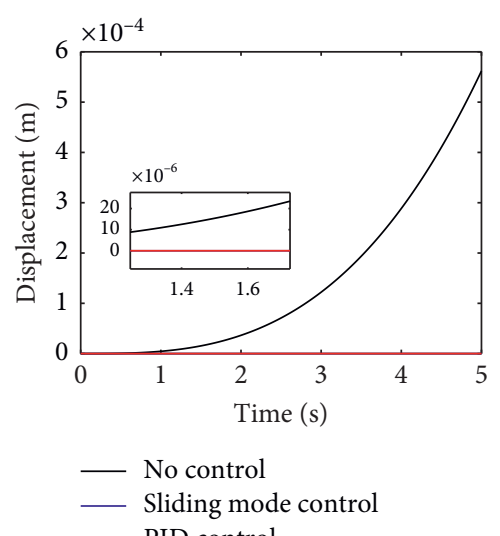

— PID control

(d)

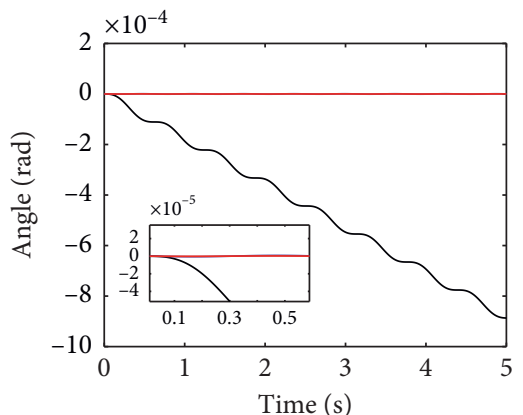

- No control

— Sliding mode contro

— PID control

(b)

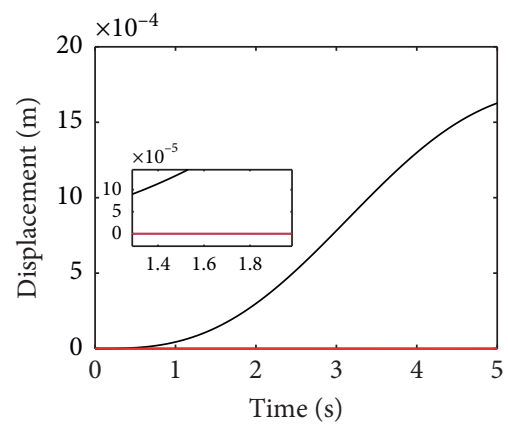

- No control
_ Sliding mode control

(e)

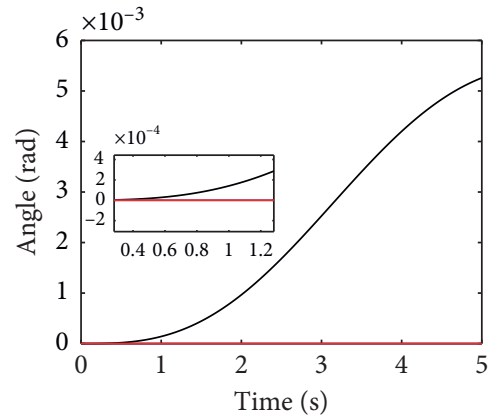

- No control

_ Sliding mode control

— PID control

(c)

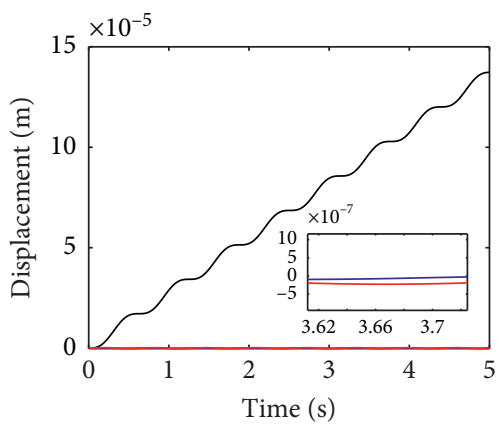

- No control

Sliding mode control

— PID control

(f)

Figure 9: Floating platform position and attitude control: (a) $\theta_{x}$, (b) $\theta_{y}$, (c) $\theta_{z}$, (d) $x$, (e) $y$, and (f) $z$.

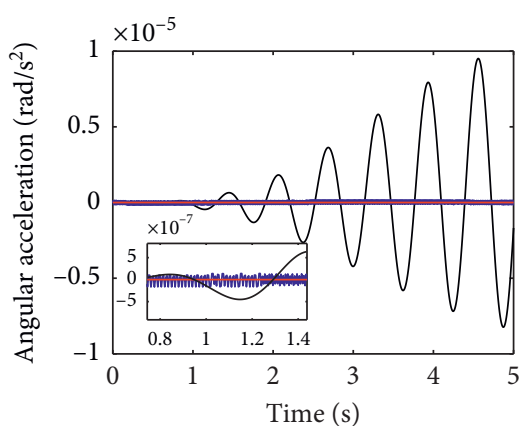

No control

Sliding mode control

PID control

(a)
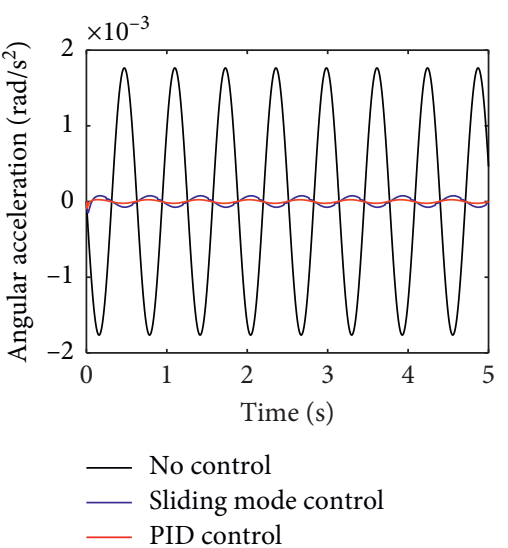

(b)

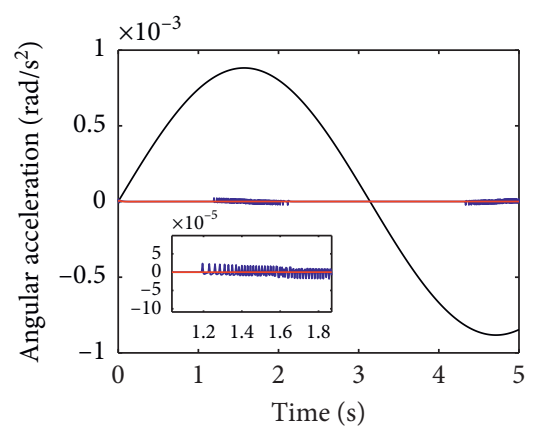

No control

Sliding mode control

— PID control

(c)

FIgURe 10: Continued. 


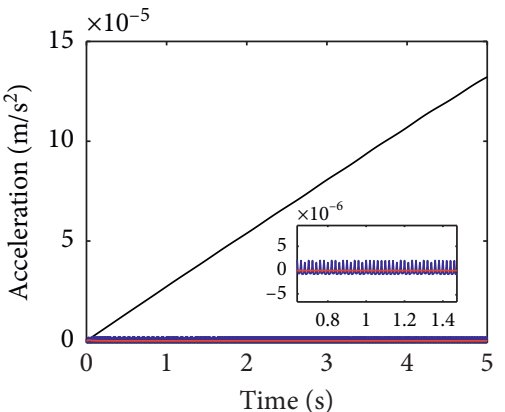

_ No control
- Sliding mode control
PID control

(d)

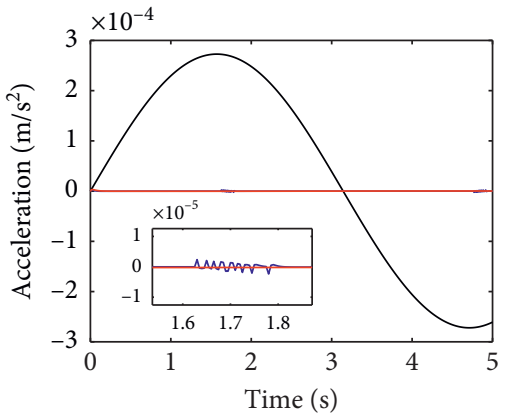

_ No control
_ Sliding mode control
PID control

(e)

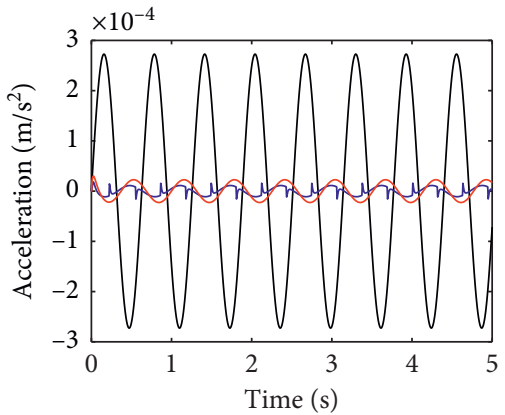

- No control

— Sliding mode control

— PID control

FIGURE 10: Floating platform acceleration and angular acceleration control.

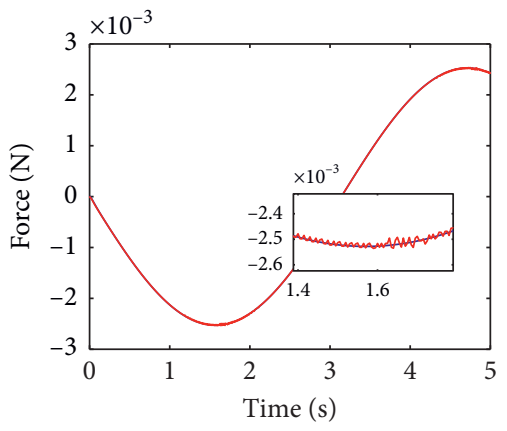

- PID control

_ Sliding mode control

(a)

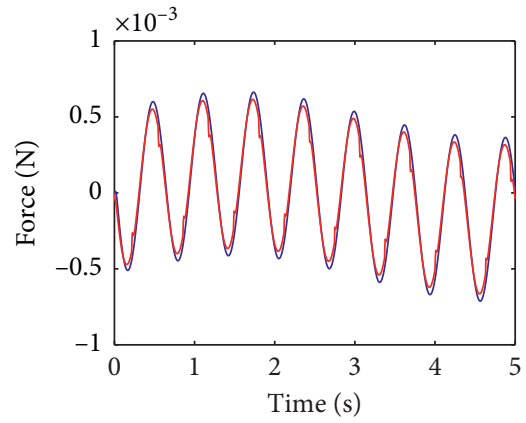

— PID control

liding mode control

(d)

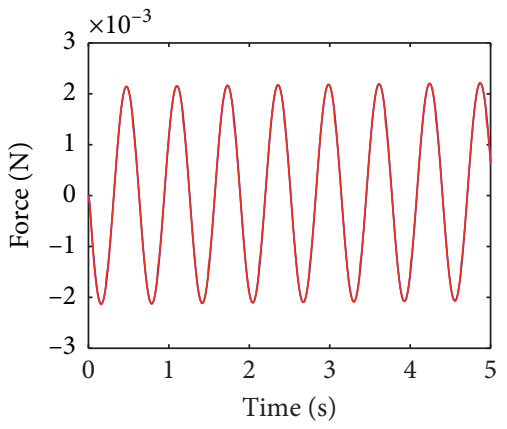

- PID control

_ Sliding mode control

(b)

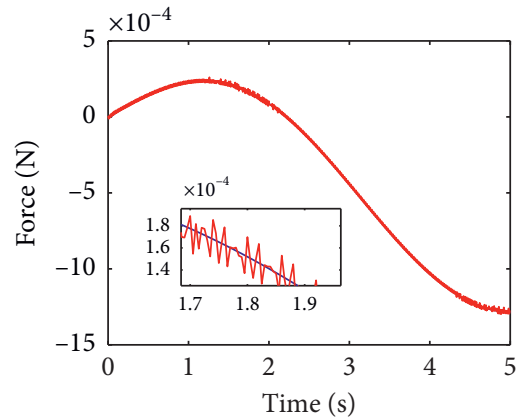

- PID control

_ Sliding mode control

(e)

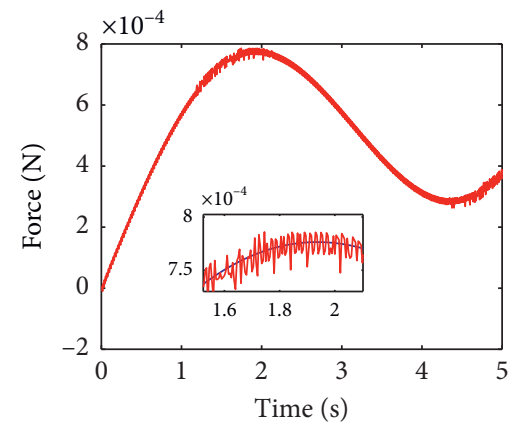

— PID control

_ Sliding mode control

(c)

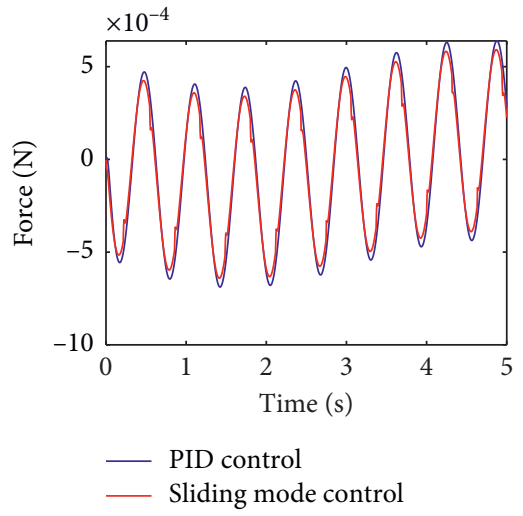

(f)

Figure 11: Comparison of PID control and slip mode control force input: (a) $F_{1 x}$, (b) $F_{1 z}$, (c) $F_{2 x}$, (d) $F_{2 z}$, (e) $F_{3 x}$, and (f) $F_{3 z}$.

$$
K=\left[\begin{array}{cccccc}
k_{1} & 0 & 0 & 0 & 0 & 0 \\
0 & k_{2} & 0 & 0 & 0 & 0 \\
0 & 0 & k_{3} & 0 & 0 & 0 \\
0 & 0 & 0 & k_{4} & 0 & 0 \\
0 & 0 & 0 & 0 & k_{5} & 0 \\
0 & 0 & 0 & 0 & 0 & k_{6}
\end{array}\right] .
$$

In order to facilitate analysis, the values of $k 1 \sim k 6$ in the coefficient matrix are all equal and set to $k$. Figure 17 shows the displacement change diagram of the $z$-axis in the main vibration direction of the floating platform. It can be observed from the figure that the larger the $k$ value of the disturbance observer based on exponential convergence, the smaller the convergence of the $z$-axis displacement of the floating platform. However, the simulation shows that too 


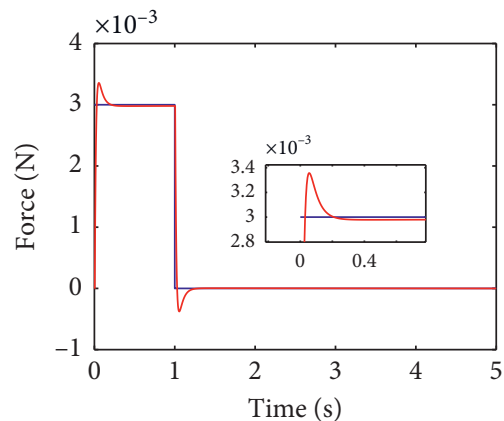

- Actual interference

(a)

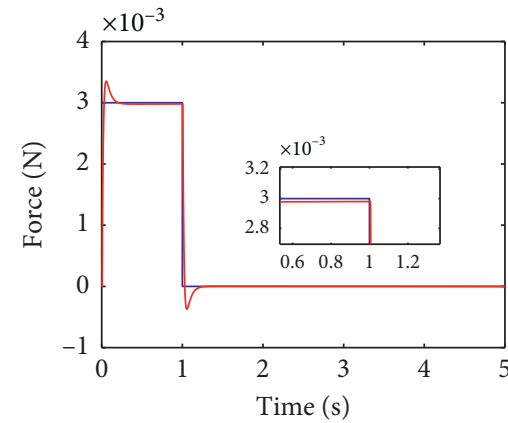

_ Actual interference

— Equivalent interference

(b)

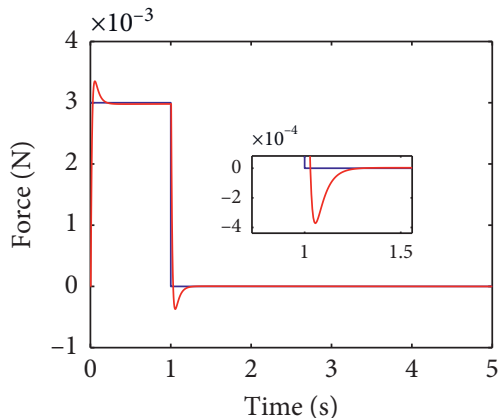

- Actual interference

_ Equivalent interference

(c)

FIGURE 12: Test results of disturbance observer: (a) $f_{d x}$, (b) $f_{d y}$, and (c) $f_{d z}$.

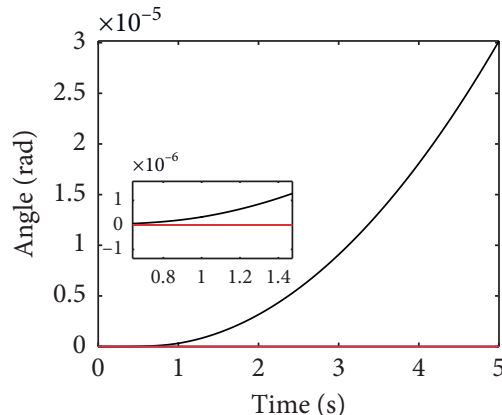

No control
_ Sliding mode control
_ PID control

(a)

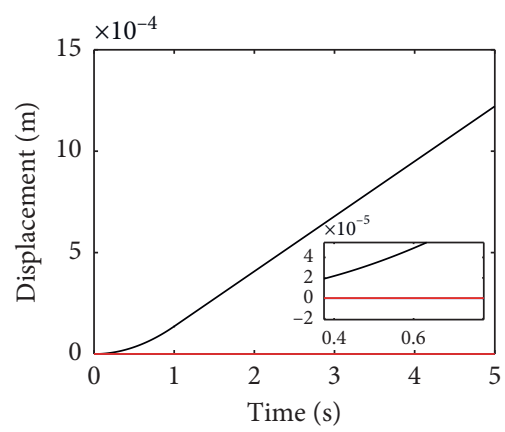

- No control

- Sliding mode control

— PID control

(d)

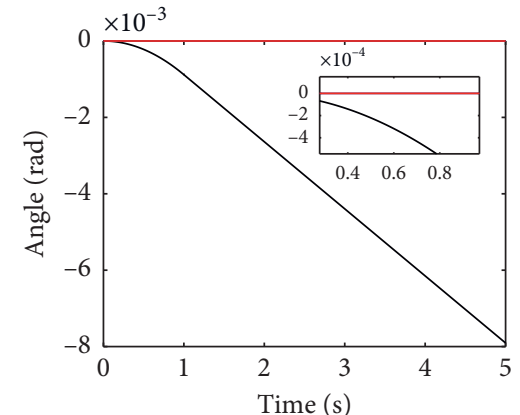

- No control

_ Sliding mode control

— PID control

(b)

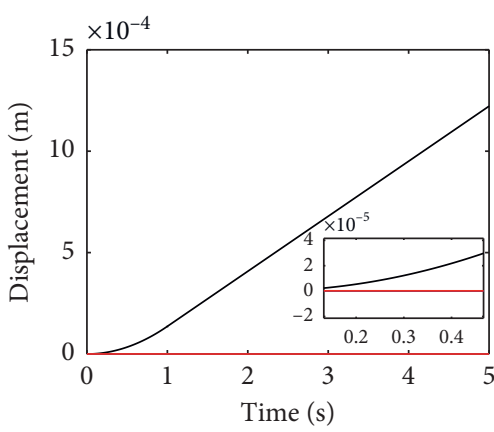

- No control

— Sliding mode control PID control

(e)

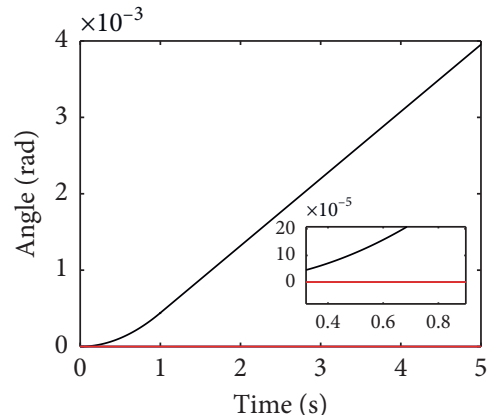

- No control

— Sliding mode control

— PID control

(c)

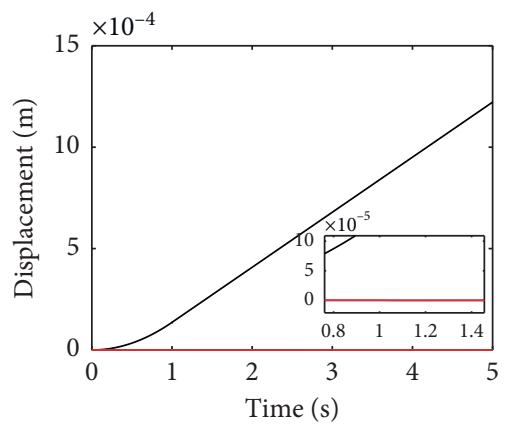

- No control

Sliding mode control PID control

(f)

FIGURE 13: Floating platform displacement and posture control: (a) $\theta_{x}$, (b) $\theta_{y}$, (c) $\theta_{z}$, (d) $x$, (e) $y$, and (f) $z$. 

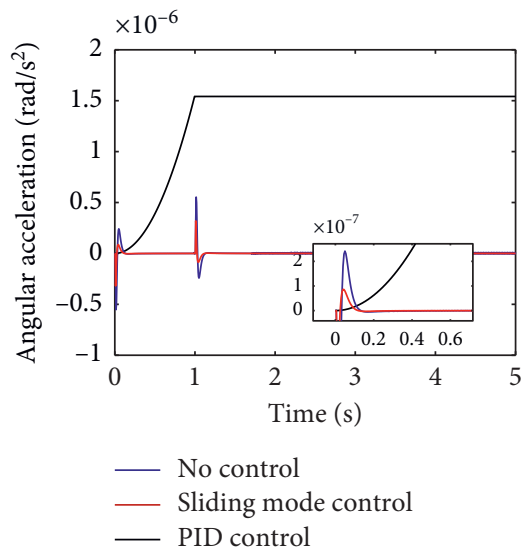

(a)

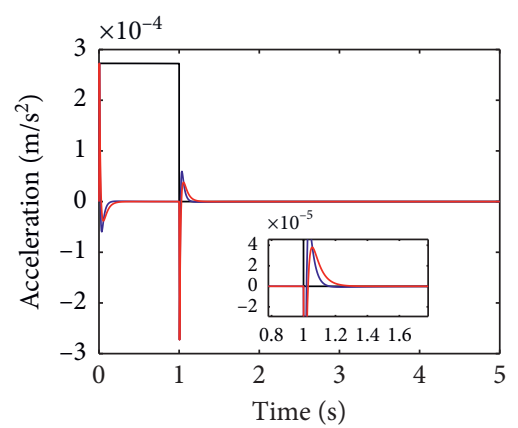

No control
— Sliding mode control
_ PID control

(d)

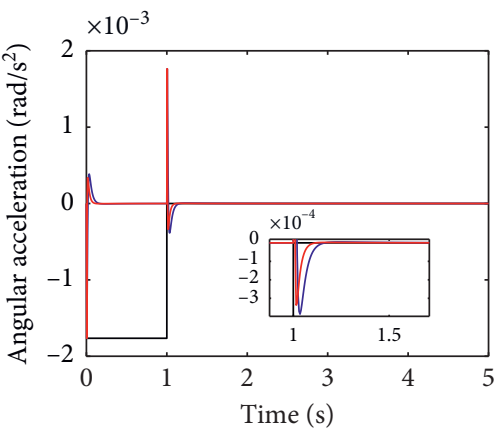

- No control

— Sliding mode control

— PID control

(b)
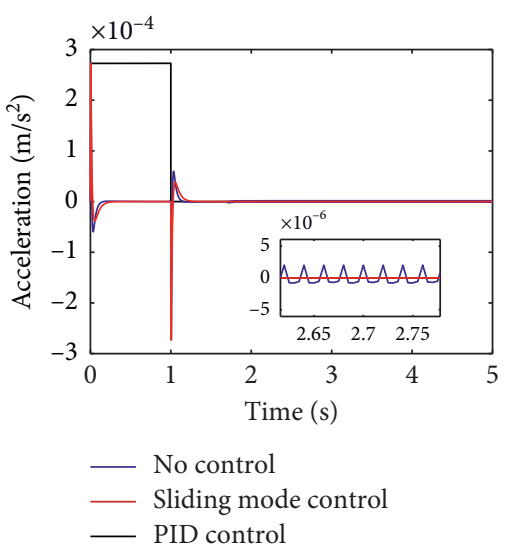

(e)

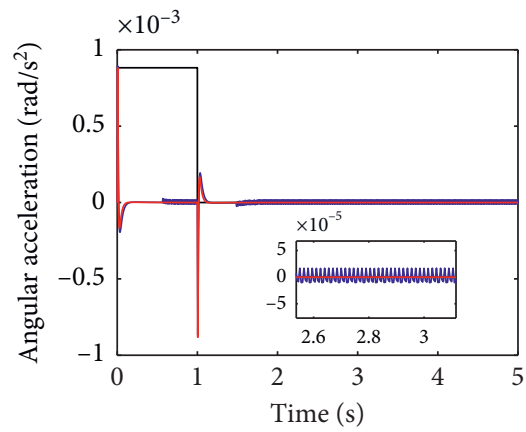

- No control

_ Sliding mode control

— PID control

(c)

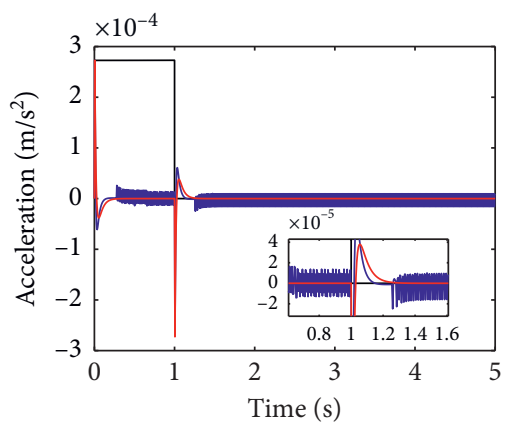

_ Sliding mode control

- PID control

(f)

FIGURE 14: Floating platform acceleration and angular acceleration control: (a) $\ddot{\theta}_{x}$, (b) $\ddot{\theta}_{y}$, (c) $\ddot{\theta}_{z}$, (d) $\ddot{x}$, (e) $\ddot{y}$, and (f) $\ddot{z}$.

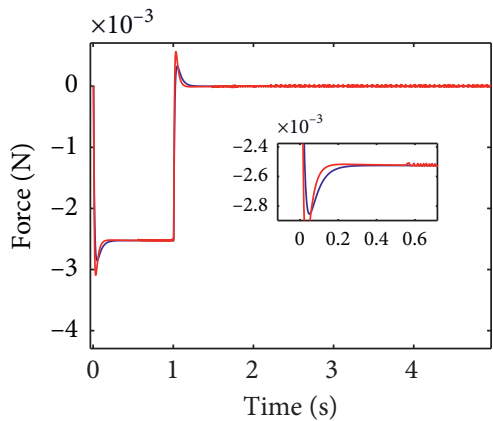

ID control

Sliding mode control

(a)

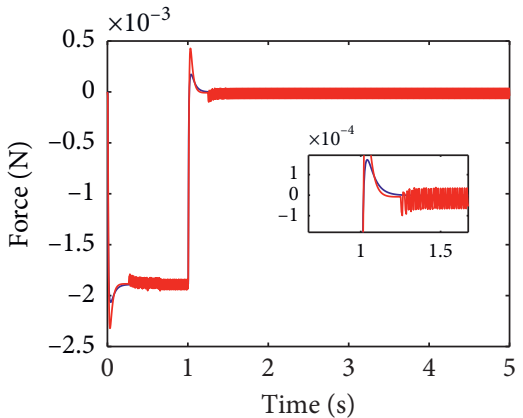

- PID control

Sliding mode control

(b)

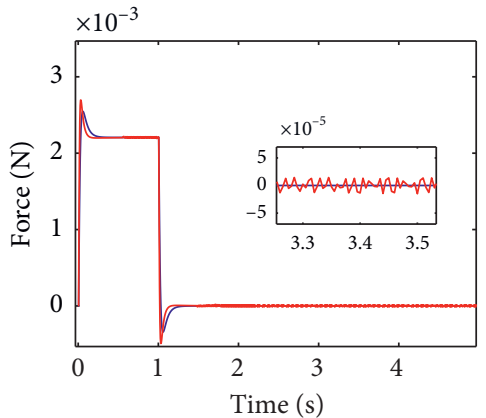

PID control

Sliding mode control

(c)

FIgURE 15: Continued. 


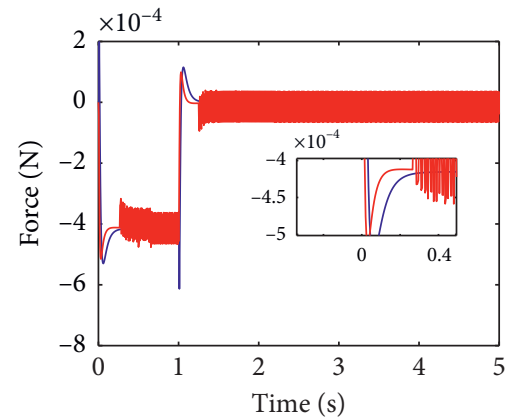

- PID control

— Sliding mode control

(d)

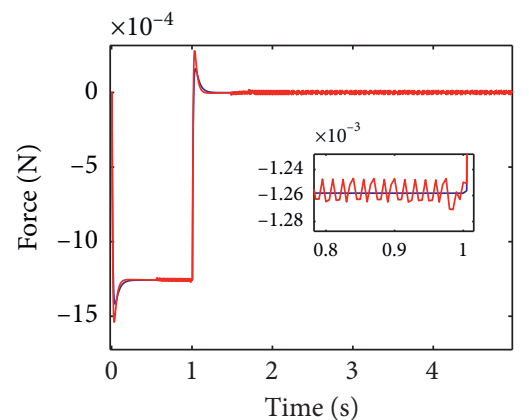

- PID control

_ Sliding mode control

(e)

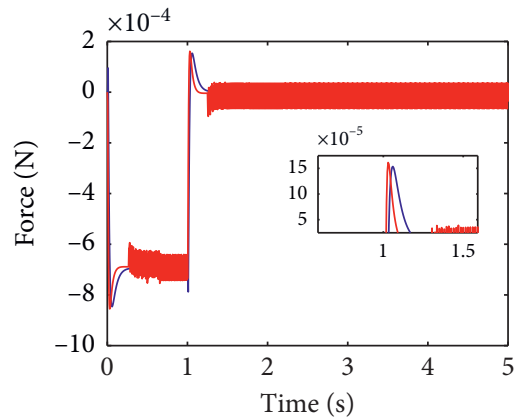

- PID control

_ Sliding mode control

(f)

FIGURE 15: Comparison of PID control with slip mode control force input.

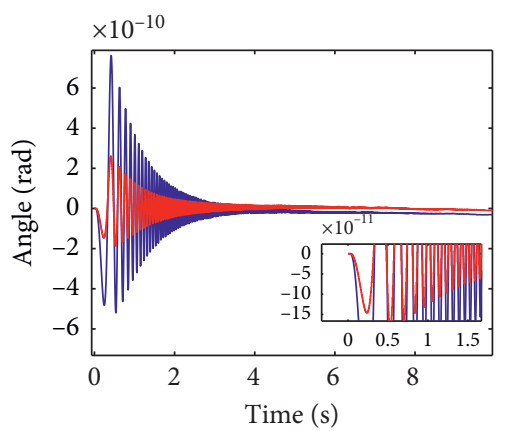

_ Sliding mode control — PID control

(a)

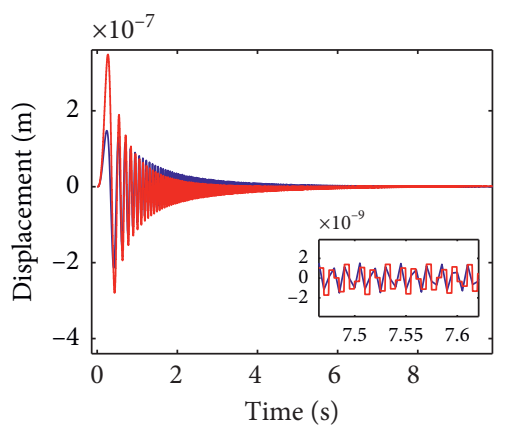

— Sliding mode control PID control

(d)

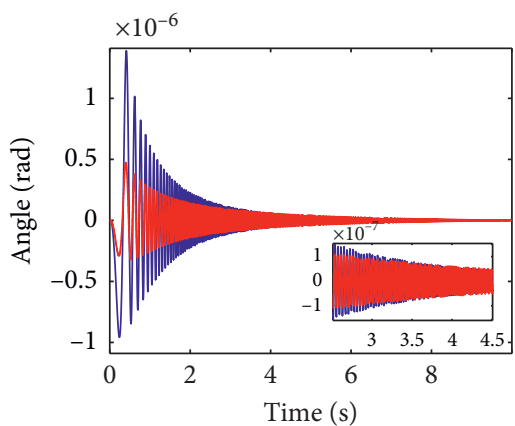

_ Sliding mode control — PID control

(b)

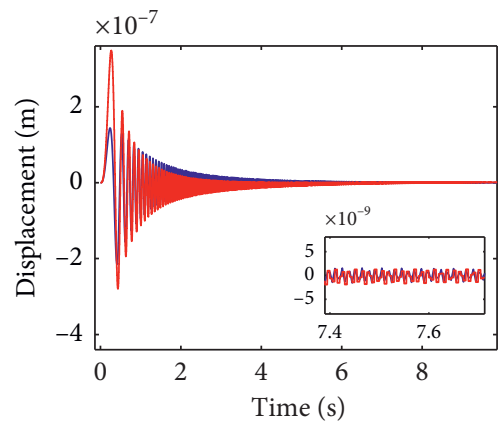

_ Sliding mode control — PID control

(e)

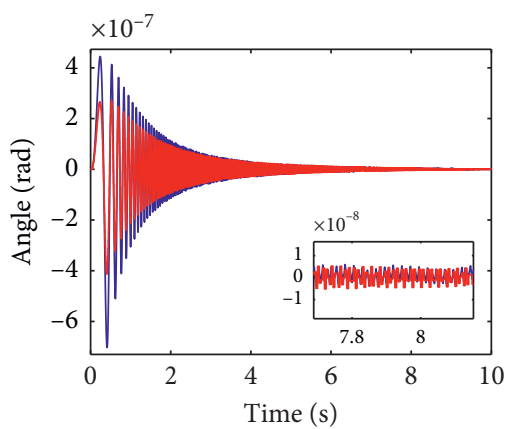

_ Sliding mode control — PID control

(c)

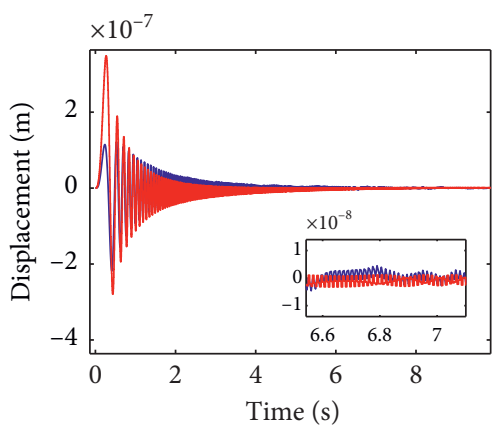

- Sliding mode control PID control

(f)

Figure 16: Changes in floating platform position and posture under sweep disturbance: (a) $\theta_{x}$, (b) $\theta_{y}$, (c) $\theta_{z}$, (d) $x$, (e) $y$, and (f) $z$. 


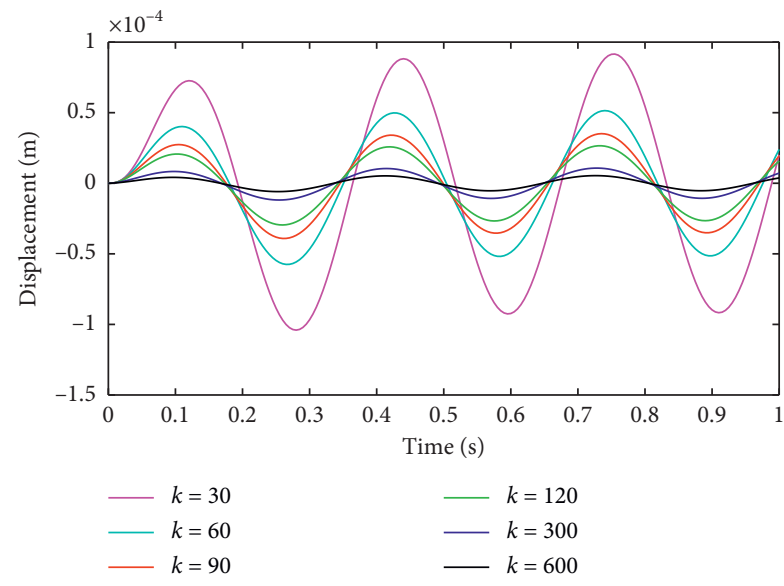

FIGURE 17: $z$-axis displacement of the floating platform.

large a value of $k$ leads to a divergent trend of $z$-axis displacement and control failure. In summary, the coefficient $k$ used in this article is generally set to 60 .

\section{Conclusion}

In this paper, a cosimulation virtual prototype model was designed to study the vibration isolation and positioning performance of the noncontact 6-DOF platform in the space microgravity environment. Based on the Kane dynamics method combined with the coordinate conversion method to carry on the dynamic modeling of the platform, a 6-DOF sliding mode robust controller based on the approach rate was designed, which has the advantages of strong antidisturbance and fast response speed. A 6-DOF disturbance observer based on exponential convergence was designed to predict the disturbance force and solve the chattering problem of sliding mode control to the greatest extent. In order to further verify the proposed model, a cosimulation model was established using ADAMS combined with MATLAB/Simulink, and 6-DOF PID control, sliding mode control, and disturbance observer programs were developed through $S$-function. The simulation results show that the control system can be well decoupled to achieve 6-DOF independent control, and the floating platform can be accurately positioned at the millimeter and micrometer levels. Among them, the adjustment time of sliding mode control is shorter than that of PID control by more than $90 \%$. In the simulation of low-frequency vibration isolation, it is found that the 6-DOF disturbance observer can well fit the actual disturbance effect, indicating that the disturbance observer can well compensate the disturbance force in the low-frequency range $(0.01-10 \mathrm{~Hz})$ and thus effectively reduce the chatter of sliding mode control. In the step disturbance simulation, it can be seen that, in the face of sudden disturbance, the sliding mode control is robust and can better control the acceleration of the platform, making the acceleration floating range only less than $20 \%$ of the PID control. In the frequency sweep disturbance simulation with a magnitude of $1 \mathrm{mN}$, the sliding mode control keeps the floating platform absolutely still, and the maximum displacement produced is less than 1 $\mu \mathrm{m}$, to achieve vibration isolation control. In summary, the 6-DOF sliding mode robust controller based on approach rate combined with the 6-DOF disturbance observer based on exponential convergence can complete the pointing and vibration isolation functions of the floating platform greatly.

\section{Future Recommendation}

Future research work will focus on the following two aspects:

(1) Improve the 6-DOF control algorithm in this paper, use the new sliding mode control algorithm in recent years (such as global SMC or SMC based on a genetic algorithm) to extend to six degrees of freedom, and use it on the virtual prototype of the noncontact 6DOF platform

(2) If the conditions are ripe, a prototype will be built to conduct field experiments to verify the virtual prototype model and theoretical algorithms and continue to improve

\section{Data Availability}

The data used to support the findings of this study are available from the corresponding author on reasonable request.

\section{Conflicts of Interest}

The authors declare that they have no conflicts of interest.

\section{Acknowledgments}

This work was supported by the National Natural Science Foundation of China (Grant nos. 61973207, 51875363, and 51605271), Shanghai Rising-Star Program (Grant no. 20QA1403900), the Natural Science Foundation of Shanghai (Grant no. 19ZR1474000), and the State Key Laboratory of Mechanics and Control of Mechanical Structures (Nanjing University of Aeronautics and Astronautics, Grant no. MCMS-E-0320G01).

\section{References}

[1] Z. Zhenhua, Y. Lei, and P. Shiwei, "Jitter environment analysis for micro-precision spacecraft," Spacecraft Environment Engineering, vol. 6, 2009.

[2] D.-L. Xu, Z. Zhao, and J.-X. Zhou, "Design and analysis of an adjustable pneumatic vibration isolator with quasi-zero-stiffness characteristic," Journal of Hunan University, vol. 6, 2013.

[3] X. Huang, Z. Zhang, J. Sun, Z. Zhang, and H. Hua, "Analytical stiffness model of a fluid-filled U-shaped bellows based threeparameter fluid damper for micro-vibration suppression," Aerospace Science and Technology, vol. 69, pp. 357-369, 2017.

[4] D.-O. Lee, G. Park, and J.-H. Han, "Experimental study on onorbit and launch environment vibration isolation performance of a vibration isolator using bellows and viscous fluid," Aerospace Science and Technology, vol. 45, pp. 1-9, 2015.

[5] D.-O. Lee, G. Park, and J.-H. Han, "Hybrid isolation of micro vibrations induced by reaction wheels," Journal of Sound and Vibration, vol. 363, pp. 1-17, 2016. 
[6] C. Wang, Y. Chen, and Z. Zhang, "Simulation and experiment on the performance of a passive/active micro-vibration isolator," Journal of Vibration and Control, vol. 24, no. 3, pp. 453-465, 2018.

[7] W. Li, H. Huang, X. Zhou, X. Zheng, and Y. Bai, "Design and experiments of an active isolator for satellite micro-vibration," Chinese Journal of Aeronautics, vol. 27, no. 6, pp. 1461-1468, 2014.

[8] L. Bai, L. Zhou, X. Jiang, Q. Pang, and D. Ye, "Vibration in a multistage centrifugal pump under varied conditions," Shock and Vibration, vol. 2019, Article ID 2057031, 9 pages, 2019.

[9] D. Kamesh, R. Pandiyan, and A. Ghosal, "Modeling, design and analysis of low frequency platform for attenuating microvibration in spacecraft," Journal of Sound and Vibration, vol. 329, no. 17, pp. 3431-3450, 2010.

[10] T. D. Le and K. K. Ahn, "Active pneumatic vibration isolation system using negative stiffness structures for a vehicle seat," Journal of Sound Vibration, vol. 333, no. 5, pp. 1245-1268, 2014.

[11] H. Chen, Y. Wang, L. I. Jia-Quan, and L. U. Yang, "Control of electromagnetic suspension vibration isolator based on LMS algorithm with saturation constraint," Journal of Vibration Shock, vol. 31, no. 13, pp. 125-128, 2012.

[12] Q. Wu, H. Yue, R. Liu, L. Ding, and Z. Deng, "Simulation of multi-closed loop control with feed forward control of microvibration isolation platform," in ASME 2014 International Mechanical Engineering Congress and ExpositionAmerican Society of Mechanical Engineers (ASME), New York, NY, USA, Article ID V04AT04A006, 2014.

[13] Q. Zhang, C. Li, J. Zhang, and X. Zhang, "Synchronized motion control and precision positioning compensation of a 3-DOFs macro-micro parallel manipulator fully actuated by piezoelectric actuators," Smart Materials and Structures, vol. 26, no. 11, 2017.

[14] Q. Luo, D. Li, and J. Jiang, "Analysis and optimization of microvibration isolation for multiple flywheel systems of spacecraft,” Aiaa Journal, vol. 54, no. 5, pp. 1719-1731, 2016.

[15] W. Ying, K. Yu, J. Jian, and Z. Rui, "Dynamic modeling and robust nonlinear control of a six-DOF active micro-vibration isolation manipulator with parameter uncertainties," Mechanism Machine Theory, vol. 92, pp. 407-435, 2015.

[16] Y. Kong and H. Huang, "Vibration isolation and dual-stage actuation pointing system for space precision payloads," Acta Astronautica, vol. 143, pp. 183-192, 2018.

[17] Y.-K. Zhang, W.-B. Dong, W. Liu et al., "Verification of the microgravity active vibration isolation system based on parabolic flight," Microgravity Science and Technology, vol. 29, no. 6, pp. 415-426, 2017.

[18] Y. Yu, S. Chen, and Y. Wang, "Cascade active disturbance rejection optimal control for microgravity active vibration isolation system," in Proceedings of the 2017 32nd Youth Academic Annual Conference of Chinese Association of Automation (YAC), pp. 602-607, IEEE, Hefei, Anhui, May 2017.

[19] Y. Yun, L. Wang, B. Zhang, Y. Tian, and T. Zhang, "Design, experiments and multidisciplinary optimization of 2 degreesof-freedom electromagnetic actuator for application in space vibration isolation," Advances in Mechanical Engineering, vol. 9, no. 12, Article ID 1687814017745675, 2017.

[20] J. Li and W. He, "Modeling and analysis of a biaxial noncontact Lorentz force actuator," IEEE Transactions on Magnetics, vol. 55, no. 4, pp. 1-9, 2019.

[21] X. Sun, B. Yang, L. Zhao, and X. Sun, "Optimal design and experimental analyses of a new micro-vibration control payload-platform," Journal of Sound and Vibration, vol. 374, pp. 43-60, 2016.

[22] X. Zhang, X. Ding, D. Wu et al., "A component-level frequency tunable isolator for vibration-sensitive chips using SMA beams," Review of Scientific Instruments, vol. 87, no. 6, Article ID 066106, 2016.

[23] A. Stabile, G. S. Aglietti, G. Richardson, and G. Smet, “Design and verification of a negative resistance electromagnetic shunt damper for spacecraft micro-vibration," Journal of Sound and Vibration, vol. 386, pp. 38-49, 2017.

[24] Q. Zhang, J. Zhao, Y. Peng, H. Pu, and Y. Yang, "A novel amplification ratio model of a decoupled XY precision positioning stage combined with elastic beam theory and Castigliano's second theorem considering the exact loading force," Mechanical Systems and Signal Processing, vol. 136, Article ID 106473, 2020.

[25] Q. Zhang, C. Li, J. Zhang, and J. Zhang, "Smooth adaptive sliding mode vibration control of a flexible parallel manipulator with multiple smart linkages in modal space," Journal of Sound and Vibration, vol. 411, pp. 1-19, 2017.

[26] X. Sun, J. Xu, X. Jing, and L. Cheng, "Beneficial performance of a quasi-zero-stiffness vibration isolator with time-delayed active control," International Journal of Mechanical Sciences, vol. 82, pp. 32-40, 2014.

[27] C. Cheng, S. Li, Y. Wang, and X. Jiang, "On the analysis of a high-static-low-dynamic stiffness vibration isolator with time-delayed cubic displacement feedback," Journal of Sound and Vibration, vol. 378, pp. 76-91, 2016.

[28] M. Moshrefi-Torbati, J. A. Forrester, A. I. J. Forrester, A. J. Keane, M. J. Brennan, and S. J. Elliott, "Novel active and passive anti-vibration mountings," Journal of Sound and Vibration, vol. 331, no. 7, pp. 1532-1541, 2012.

[29] A. Carrella, M. J. Brennan, T. P. Waters, and V. Lopes Jr., "Force and displacement transmissibility of a nonlinear isolator with high-static-low-dynamic-stiffness," International Journal of Mechanical Sciences, vol. 55, no. 1, pp. 22-29, 2012.

[30] M. A. Acar and C. Yilmaz, "Design of an adaptive-passive dynamic vibration absorber composed of a string-mass system equipped with negative stiffness tension adjusting mechanism," Journal of Sound and Vibration, vol. 332, no. 2, pp. 231-245, 2013.

[31] L. I. Zong-Feng, Q. Liu, and W. J. Ren, "Dynamic modeling for a space high quality microgravity active vibration isolation system," Journal of Vibration Shock, vol. 29, no. 7, 2010.

[32] N. M. Qi, W. H. Zhang, and J. Z. Gao, "The primary discussion for the ground simulation system of spatial microgravity," Aerospace Control, vol. 29, pp. 95-100, 2011.

[33] S. Tang, S. Yuan, and Y. Zhu, "Deep learning-based intelligent fault diagnosis methods toward rotating machinery," IEEE Access, vol. 8, pp. 9335-9346, 2019.

[34] J.-L. Li, J.-B. Wang, and W. He, "Electromechanical cosimulation analysis for contactless positioning and vibration isolation platform," Journal of ZheJiang University (Engineering Science), vol. 53, no. 1, pp. 146-157, 2019.

[35] Q. Wu, H. Yue, R. Liu, L. Ding, and Z. Deng, "Parametric design and multiobjective optimization of maglev actuators for active vibration isolation system," Advances in Mechanical Engineering, vol. 6, Article ID 215358, 2014.

[36] D. A. Haghighi and S. Mobayen, "Design of an adaptive supertwisting decoupled terminal sliding mode control scheme for a class of fourth-order systems," ISA Transactions, vol. 75, pp. 216-225, 2018.

[37] S. Mobayen, "Chaos synchronization of uncertain chaotic systems using composite nonlinear feedback based integral 
sliding mode control," ISA Transactions, vol. 77, pp. 100-111, 2018.

[38] S. Mobayen, "Design of LMI-based sliding mode controller with an exponential policy for a class of underactuated systems," Complexity, vol. 21, no. 5, pp. 117-124, 2016.

[39] S. Mobayen, "A novel global sliding mode control based on exponential reaching law for a class of underactuated systems with external disturbances," Journal of Computational and Nonlinear Dynamics, vol. 11, no. 2, 2016. 